\author{
Matej Šekli \\ Filozofska fakulteta Univerze v Ljubljani \\ Inštitut za slovenski jezik Frana Ramovša ZRC SAZU
}

\title{
Glagolska vezljivost v jeziku Brižinskih spomenikov
}

V prispevku je obravnavana glagolska vezljivost (verbalna valenca), in sicer predvsem glagolska vezava (verbalna rekcija) glagolov, ki se pojavljajo v jeziku Brižinskih spomenikov (zapisani v obdobju 972-1039), najstarejši dokumentirani časovni različici slovenščine. Prikazana je vezljivostna oziroma vezavna tipologija glagolov, pri čemer so vezljivostne oziroma vezavne lastnosti posameznega glagola lahko pogojene s pomenom glagolskega korena, glagolske pripone in/ali glagolske predpone. Stanje v jeziku Brižinskih spomenikov je primerjano s stanjem v stari cerkveni slovanščini (9. stoletje) in rekonstruiranim praslovanskim stanjem. Ugotovljene so inovacije na časovni osi praslovanščina - slovenščina 10. stoletja.

The article discusses verb valency with special regard to case government as observable in the Freising Monuments (Sln. Brižinski spomeniki), which, dating to between 972 and 1039 $\mathrm{AD}$, represent the oldest documented chronological variant of Slovene. A general typology of valence/government is built, deriving the various attested patterns from the lexical meaning of the verbal root, the type of the verbal suffix, and/or the verbal prefix. The system directly observable in the language of the Freising Monuments is then effectively compared with that of Old Church Slavonic (9th c. AD) and, ultimately, Proto-Slavic. This strategy is used to enable successful identification of the innovatory and progressive changes typical of 10 th century Slovene in relation to the reconstructed Proto-Slavic stage.

\section{Uvod}

\subsection{Analitični in sintetični pristop v skladnji}

Skladnja (sintaksa) (iz gr. $\sigma \dot{v} v \tau \alpha \xi ı \varsigma<* \sigma v v-\tau \alpha \dot{\alpha} \gamma-\sigma l-\varsigma$ 'sestava, ureditev, razvrstitev, ustroj' $\leftarrow \sigma v v-\tau \alpha \dot{\sigma} \sigma \sigma \omega$, at. $\sigma v v-\tau \dot{\alpha} \tau \tau \omega<* \sigma v v-\tau \dot{\alpha} \gamma-j \omega$ 'postavljam skupaj; urejam, združujem v celoto, zlagam') je jezikoslovna veja, ki preučuje stavke in njihove dele, in sicer v okviru tako analitičnega pristopa, v okviru katerega jo zanima, kako so stavki zgrajeni, kot sintetičnega pristopa, v okviru katerega jo zanima, kako se stavki tvorijo. ${ }^{1} \mathrm{~V}$ nadaljevanju je na kratko najprej predstavljen analitični pristop pri preučevanju prostega stavka, ki v skladnji analizira zgradbo prostega stavka in njegovih delov tako s stališča jezikovnega sistema (sosirjanski langue) kot s stališča besedila,

${ }^{1}$ Toporišičeva skladnja na primer upošteva oba metodološka pristopa: »Skladnja ali sintaksa je poseben del slovničnega nauka o jeziku. Uči, kako se delajo (oz. kako so narejene) pravilne povedi in njihovi deli« (Toporišič 2000: 487). 
tj. jezikovnega sistema v sporazumevanju (sosirjanski parole). Predmet analize prostega stavka in njegovih delov so s stališča jezikovnega sistema lahko besedne zveze (oblikovni vidik), pomenske/udeleženske vloge besednih zvez (pomenski vidik) in stavčni členi besednih zvez (skladenjski vidik), s stališča besedila pa prvine členitve po aktualnost, tj. izhodišče/tema/topic - prehod - jedro/rema/focus (besedilni vidik). ${ }^{2}$

\subsubsection{Oblikovni (formalni) vidik}

Besedne zveze (tudi stavčne fraze) ali sintagme (iz gr. $\sigma \delta v-\tau \alpha \gamma-\mu \alpha$, Gsg $\sigma v \nu-\tau \alpha \dot{\gamma} \gamma-\mu \alpha \tau$ $o \varsigma$ 'zloženost', prim. zgoraj) so zveze besed, ki so sestavine prostega stavka (stavčni členi). Vsaka besedna zveza, tako nezložena kot zložena, ima jedro ali odnosnico (to je oblikovno jedrna in ob pojavljanju določila pomensko določena sestavina besedne zveze), podredno zložena pa tudi določilo (to je oblikovno nejedrna in pomensko določujoča sestavina besedne zveze). Jedro besedne zveze so različne besedne vrste, zato razlikujemo različne besednozvezne vrste, ${ }^{3}$ in sicer so to glagolske, samostalniške, pridevniške, prislovne, predložne in vezniške besedne zveze. ${ }^{4}$

\subsubsection{Pomenski (semantični) vidik}

S pomenskega (semantičnega) vidika ima vsaka besedna zveza pomen oziroma svojo pomensko/semantično/udeležensko vlogo. Pomen samostalniške in predložne besedne zveze določa pomen glagola, ob katerem se le-ti pojavljata.

Glagoli imajo glede na svoj konkretni leksikalizirani slovarski (leksikalni) pomen bolj abstraktno gledano kategorialni slovarski pomen dejanje (actio, Gsg actionis) ali stanje (status, Gsg statūs), posledično je mogoče ločiti glagole dejanja in

${ }^{2} \mathrm{~V}$ pričujočem besedilu se uporabljata strokovna izraza prosti stavek in zloženi stavek (Bajec, Kolarič, Rupel 1956: 283, 297) (podobno na primer tudi nem. der einfache Satz in der zusammengesetzte Satz (Einsenberg 1998: 624, 755), it. frase semplice in frase complessa (Dardano, Trifone 1995: 95, 443)), saj oba poimenujeta istovrstni jezikovni pojavnosti, tj. zgradbeni enoti (oblikovni vidik), za razliko od strokovnih izrazov stavek in poved (Toporišič 2000: 488-489), ki se ne nanašata na istovrstni jezikovni pojavnosti, prvi namreč poimuje zgradbeno (stavek je »[z]veza besed, zbranih okrog osebne glagolske oblike, in sicer na podlagi glagolske vezljivosti in družljivosti« (Toporišič 1992: 309)) (oblikovni vidik), drugi pa besedilno enoto (poved je »[s]kladenjska enota $\mathrm{v}$ vlogi besedila ali samostojna enota le-tega « (Toporišič 1992: 199)) (besedilni vidik).

${ }^{3}$ Pojem besednozvezna vrsta se pojavlja v Toporišič 2000: 558.

${ }^{4} \mathrm{~V}$ različnih slovničnih tradicijah se pojavlja različno število besednozveznih vrst, in sicer povsod nista samoumevni predvsem predložna in vezniška besedna zveza. Nekatera skladenjska dela poznajo tako predložno kot vezniško besedno zvezo (Eisenberg 1998: 103), nekatera samo predložno (Dardano, Trifone 1995: 103), nekatera nobene od obeh (Toporišič 1982: 39-131, 2000: 557-606; Žele 2008: 39-41; Smolej 2011: 53-55). Določitev omenjenih besednih zvez se zdi s skladenjskega vidika upravičena, saj imata le-ti samostojne stavčnočlenske vloge: a) predložna besedna zveza: predložni predmet, prislovno določilo, »samostalniški« neujemalni prilastek; b) vezniška besedna zveza: prislovno določilo, povedkovo določilo, »samostalniški« neujemalni prilastek. 
glagole stanja. ${ }^{5}$ Glagoli dejanja (verba actionis) se lahko delijo na glagole premikanja (verba movendi) ter glagole nepremikanja, slednji pa še natančneje na glagole prizadevanja (verba afficiendi) in glagole proizvajanja (verba efficiendi). Predvsem glagoli prizadevanja imajo različne pomenske skupine; to so na primer glagoli zaznavanja (verba sentiendi), dajanja (verba dandi), polnjenja (verba plendi), jemanja (verba capiendi), rekanja (verba dicendi), imenovanja (verba nominandi), učenja (verba docendi) ipd. Glagoli stanja ali stativi (verba statūs, verba stativa) so esivi (verba essiva od lat. esse 'biti'), tj. glagoli s pomenom doseženo stanje (to so glagoli na *-ěl'a-ti

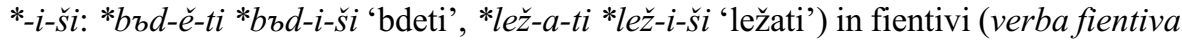
od lat. fieri 'postati'), tj. glagoli s pomenom prehajanje v stanje (to so nekateri glagoli na *-nQ- $t i{ }^{*}$-ne-š $i$ : *sbx-nQ- $t i{ }^{*} s b x$-ne-š $i$ 'sahniti, usihati'). ${ }^{6}$ Glagoli so lahko polnopomenski (verba concreta) s polnim slovarskim pomenom ali nepolnopomenski (verba abstracta) z oslabljenim slovarskim pomenom, nastalim s slabljenjem polnega slovarskega pomena polnopomenskega glagola. $^{7}$

Diahrono gledano ima glagol prvotno polni slovarski (leksikalni) pomen, ki se s slabljenjem, šibitvijo lahko spremeni v nepolni slovarski pomen in nadalje v slovnični (gramatični) pomen (pri tem se leksem spremeni v morfem - pojav se imenuje gramatikalizacija), pri čemer je posledica spreminjanja pomena glagola spreminjanje njegove skladenjske/stavčnočlenske vloge. Sinhrono gledano se glagoli glede na vrsto pomena in posledično skladenjsko tako delijo v tri skupine; to so: a) predikativni glagoli (tj. polnopomenski glagol s polnim slovarskim pomenom, ki lahko samostojno nastopajo v skladenjski vlogi glagolskega povedka (verbalnega predikata)); b) kopulativni glagoli ali glagoli kopula/vez (tj. nepolnopomenski glagoli z nepolnim, oslabljenim slovarskim pomenom, ki ne morejo samostojno nastopati v vlogi glagolskega povedka in imajo ob sebi pridevniško oziroma samostalniško imensko povedkovo določilo, s katerim tvorijo pridevniški oziroma samostalniški imenski povedek (adjektivni oziroma substantivni nominalni predikat)); c) pomožni glagoli (glagoli s slovničnim pomenom, ki so del zložene glagolske oblike, znotraj katere izražajo slovnične kategorije glagola, kot so oseba, število, spol).

${ }^{5} \mathrm{~V}$ pričujočem delu so predstavljene samo tiste najosnovnejše pomenske skupine glagolov, ki so uporabljene pri analizi glagolske vezljivosti v jeziku Brižinskih spomenikov. Zelo natančna pomenska delitev glagolov v slovenščini, izdelana $\mathrm{z}$ modelom t. i. pomenske piramide (glagoli glede na kompleksnost pomena so primarni, (nosilni) temeljni/elementarni, ki pomensko vsebujejo primarne, in (višji) specializirani, ki pomensko vsebujejo (nosilne) temeljne/elementarne; glede na slovarski pomen se znotraj vseh treh skupin pojavljajo glagoli, ki poimenujejo telesno in duševno stanje/proces (ki pomensko vsebujejo glagola biti, imeti), netvorna dogajanja in procese (ki pomensko vsebujejo glagola delati se, postajati), tvorna dejanja in procese (ravnanje, upravljanje, ustvarjanje) (ki pomensko vsebujejo glagola delati, dati), premikanje), je prikazana na primer v Žele 2001: 113-230.

${ }^{6}$ Pomenska analiza praslovanskih glagolov po glagolskih vrstah in razredih je prikazana na primer v Šekli 2011.

${ }^{7}$ Delitev glagolov na verba concreta in verba abstracta se pojavlja na primer v Miklosich 1883: 261-263. 
Samostalniki oziroma samostalniške besedne zveze imajo v prostem stavku različne pomenske/udeleženske vloge (ang. semantic roles, rus. семантические роли). $\mathrm{V}$ pričujočem besedilu je merilo določanja pomenske/semantične/udeleženske vloge oblikovno-pomensko, in sicer sta upoštevana sklon samostalnika v tvornem (aktivnem) stavku in kategorialni slovarski pomen glagola (dejanje, stanje, vez). ${ }^{8}$ Teži se k temu, da se pomenske/udeleženske vloge definirajo čim bolj abstraktno, kategorialno in se v čim večji meri pokrivajo s pomeni sklonov oziroma stavčnih členov in $\mathrm{z}$ besedotvornimi pomeni besedotvornih morfemov. ${ }^{9}$ To izhaja iz težnje slovničnega (ne slovarskega!) jezikoslovnega opisa po čim večji prekrivnosti pojavov na različnih ravninah jezikovnega sistema (pomenski, skladenjski, oblikovni). Tako so predstavljene le najbolj osnovne pomenske/udeleženske vloge.

Osebkov imenovalnik (subjektivni nominativ, nominativus subiectivus) ima $\mathrm{v}$ tvornih stavkih pomene vršilec/vršilnik dejanja (agens, Gsg agentis) ob glagolih s pomenom dejanje, nosilec/nosilnik stanja ob glagolih s pomenom stanje, nosilec/nosilnik lastnosti ob pridevniškem imenskem povedku in nosilec/nosilnik istovetnosti (identitete) ob samostalniškem imenskem povedku. ${ }^{10}$ Predmetni tožilnik (objektivni

${ }^{8}$ Število pomenskih/udeleženskih vlog in merilo njihovega določanja se od avtorja do avtorja razlikuje. V slovenskem jezikoslovju je opaziti od treh osnovnih pomenskih/udeleženskih vlog (vršilec, prejemnik, prizadeto) (Orešnik 1992: 12) do zelo natančno razdelane pomenske mreže le-teh (Žele 2001, Smolej 2011, Grošelj 2011, prim. spodaj na primer pomene osebkovega imenovalnika). Udeleženske vloge so pri navedenih avtorjih določene na osnovi približno istega pomena različnih oblik, zgradb (v stavkih Slovenija ima veliko naravnih bogastev in $v$ Sloveniji je veliko naravnih bogastev imata tako Slovenija kot $v$ Sloveniji udeležensko vlogo prejemnik; Orešnik 1992: 11-13), kar pomeni hierarhično nadrejenost pomena nad obliko (z oblikovnega vidika ima v navedenih stavkih Slovenija pomen nosilca/nosilnika stanja, $v$ Sloveniji pa pomen prostor/kraj, natančneje mesto), oziroma na osnovi slovarskega pomena glagola (Žele 2001, Smolej 2011, Grošelj 2011), kar pomeni hierarhično nadrejenost (konkretnejšega) slovarskega pomena nad (abstraktnejšim) slovničnim. Zastavlja se vprašanje, ali predvsem drugi metodološki pristop še sodi na področje slovničnega (gramatičnega) ali morda ne že na področje slovarskega (leksikalnega) pomenoslovja (semantike).

${ }^{9}$ Slovarsko (leksikalno), tj. z leksemom izražena skladenjska pomena (pomenski/udeleženski vlogi) vršilec/vršilnik dejanja (agens) in nosilec/nosilnik lastnosti v prostem stavku (na skladenjski ravni) sta vzporedna slovnično (gramatično), tj. z morfemom izraženima besedotvornima pomenoma vršilec/vršilnik dejanja (nomen agentis) in nosilec/nosilnik lastnosti (nomen attributivum) v tvorjenki (na oblikovni ravni), pri čemer imata vršilec in nosilec podspol živo, vršilnik in nosilnik pa podspol neživo (za pojme vršilec/vršilnik in nosilec/nosilnik v besedotvorju prim. Toporišič 2000: 161-165, 169-172). Vsi skladenjski pomeni (pomenske/ udeleženske vloge) nimajo svojih vzporednic v besedotvornih pomenih, saj se vsi pomeni ne gramatikalizirajo, posledično je število slovarskih večje od števila slovničnih pomenov.

${ }^{10} \mathrm{~V}$ slovenskem jezikoslovju se ponekod pojavljajo natančnejše pomenske opredelitve osebkovega imenovalnika v tvornih stavkih, predvsem pomenov vršilec/vršilnik dejanja in nosilec/nosilnik stanja, na primer (prikazani so samo nekateri pogledi v časovnem vrstem zaporedju pojavljanja): vršilec dejanja (Deček je ubil lisico), nosilec dogajanja (Deček spi) (Kunst Gnamuš 1981: 42); vršilec (Micka poje lepo pesem), prejemnik (Micka se jezi, Slovenija ima 
akuzativ, accusativus obiectivus) ima v tvornih stavkih pomen prizadeto $\mathrm{v}$ širšem smislu (patiens, Gsg patientis), in sicer ob glagolih prizadevanja pomen prizadeto $\mathrm{v}$ ožjem smislu (affectum, aficirani objekt) in ob glagolih proizvajanja pomen rezultat dejanja (effectum, eficirani objekt). Predmetni dajalnik (objektivni dativ, $d a-$ tivus abiectivus) ima pomen prejemnik v širšem smislu (recipiens, Gsg recipientis), in sicer prejemnik v ožjem smislu, tj. prejemnik predmeta, in koristnik (beneficiens, Gsg beneficientis), tj. prejemnik dejanja. ${ }^{11}$ Pomeni predložnih sklonov so predmetni (objektivni), tj. v skladenjski vlogi predložnega predmeta, ali prislovni (adverbialni), tj. v skladenjski vlogi prislovnega določila.

\subsubsection{Skladenjski (sintaktični) vidik}

S skladenjskega (sintaktičnega) vidika imajo besedne zveze svoje skladenjske/ stavčnočlenske vloge. Glagol ima skladenjsko/stavčnočlensko vlogo povedka, samostalniška besedna zveza osebka in predmeta, predložna besedna zveza pa predvsem prislovnega določila (prostora/kraja, časa, načina, vzroka). Znotraj prislovnega določila prostora/kraja (adverbiale loci) se zdi smotrno razlikovati med naslednjimi podtipi: mesto (lokativni pomen, in sicer adesivni 'pri, ob', inesivni ' $\mathrm{v}$ ', superesivni 'na'), ciljno mesto (direktivni pomen, in sicer adlativni ' $\mathrm{k} / \mathrm{h}$ ', ilativni ' $\mathrm{v}$, noter', sublativni 'na'), izhodiščno mesto (ablativni pomen v širšem smislu, in sicer ablativni v ožjem smislu 'od, stran, proč', elativni 'iz', delativni 'z/s').

\subsection{Glagolska vezljivost (verbalna valenca)}

Glagolska vezljivost (verbalna valenca) je znotraj analitičnega pristopa, katerega izhodišče je oblika in cilj pomen, obvezno pojavljanje samostalnika oziroma samostalniške besedne zveze v različnih sklonih ali predložne besedne zveze z različnimi skloni ob

veliko naravnih bogastev) (Orešnik 1992: 12-13); vršilec (Peter je prodal Špeli svoj računalnik), doživljalec (Peter ima rad rože), sredstvo (Ključ je odprl vrata), sila (Poplava je odnesla most) (Golden 2000: 55); vršilec/povzročitelj/pobudnik dejanja ob glagolih tipa spreminjati/ zažigati/vzpodbujati, nosilec dejanja/dogajanja/procesa/stanja ob glagolih tipa teči/dogajati se/spreminjati se/bivati (Žele 2001: 75); vršilec dejanja (Anton je razbil okno), povzročitelj dejanja (Veter je odprt okno), pobudnik dejanja (Anton je predlagal, da bi šli v kino), nosilec dejanja ali dogajanja (Anton vsako jutro teče), nosilec stanja (Anton je hudo bolan), prizadeto (Anton je ostal brez hlač), prejemnik (Anton je dobil knjigo), sredstvo (Lepa beseda vse dose$\check{z}$ ) (Smolej 2011: 23); nosilec dejavnosti, procesa, lastnosti, in sicer pri glagolih umevanja, ki se delijo na glagole mišljenja (misliti, meniti) in glagole védenja (umeti, vedeti, znati), sta to nosilec mišljenja (mišljenjskih procesov) in nosilec védenja (védenjskih procesov), glede na slovarski pomen posameznega glagola pa natančneje še nosilec namere, spominjanja, omenjanja, znanja, poznavanja, sposobnosti, zmožnosti, razumevanja, navade ipd. (Grošelj 2011: 12, 22, passim). Podobno velja za ostale pomenske/udeleženske vloge.

${ }^{11} \mathrm{O}$ razlikovanju med prejemnikom (Janez je dal Petru knjigo) in koristnikom (Janez je dal Petru knjigo na polico) prim. Marvin 2012. 
nekem glagolu, ${ }^{12}$ medtem ko je glagolska družljivost neobvezno pojavljanje (samostalniških, pridevniških, prislovnih, predložnih, vezniških) besednih zvez ob nekem glagolu. Glagolska vezljivost je v tvornih (aktivnih) stavkih imenovalniška ali osebkova (s stališča jezikovnih sistemov z nezaznamovanim besednim redom tipa osebek-povedek-predmet »leva«) in neimenovalniška ali predmetno-prislovna (s stališča jezikovnih sistemov z nezaznamovanim besednim redom tipa osebek-povedek-predmet $» d e s n a \ll)$. Neimenovalniška glagolska vezljivost je glagolska vezava (verbalna rekcija), tj. vezava glagola z neimenovalniškim sklonom. Glede na vezljivostno oziroma vezavno tipologijo so glagoli: ${ }^{13}$ a) enovezljivi (monovalentni), nevezavni (arekcijski), neprehodni (intranzitivni): $\mathrm{Sub}_{\text {nom }}-$ Verb ${ }^{14}$ b) dvovezljivi (bivalentni), enovezavni (monorekcijski),

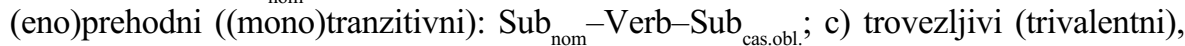
dvovezavni (birekcijski), dvoprehodni (bitranzitivni): $\mathrm{Sub}_{\text {nom }}-\mathrm{Verb}_{-} \mathrm{Sub}_{\text {cas.obl. }}-\mathrm{Sub}_{\text {cas.obl. }}$. Glagolska vezljivost oziroma glagolska vezava je bila v brezpriponsko-brezpredložnem obdobju jezika pogojena s slovarskim pomenom glagola, slovarskim pomenom samostalnika in slovničnim pomenom sklona, ${ }^{15} \mathrm{v}$ priponsko-predložnem obdobju jezika pa tudi s pomenom glagolske predpone.

\subsubsection{Brezpredponsko-brezpredložno obdobje jezika}

V brezpredponsko-brezpredložnem obdobju jezika glagoli niso imeli predpon ( ${ }^{*}$ grěti 'greti', *nesti 'nesti', *jiti 'iti') in samostalniki niso imeli predlogov (Asg *vodo 'vodo, v vodo', Gsg *vody 'vode, iz/z/od vode', Lsg *vodě 'v/na/ob vodi'), obstajali so torej le nesestavljeni glagoli in brezpredložni skloni. Glagoli so se glede na svoj slovarski pomen vezali glede na slovarski pomen samostalnika in slovnični pomen njegovega sklona. Tako se je na primer prehodni glagol (nepremikanja ali premikanja) vezal s samostalnikom ( $\mathrm{z}$ »neprostorskim« ali »prostorskim « slovarskim pomenom) v tožilniku s predmetnim pomenom prizadeto ( *grěti męso, vodo 'greti meso, vodo', *nesti męso, vodo 'nesti meso, vodo'), (prehodni in neprehodni) glagol premikanja s samostalnikom (s »prostorskim« slovarskim pomenom) v tožilniku s prislovnim pomenom ciljno mesto ("nesti, jiti vodo 'nesti, iti v/na vodo') in v ločilniškem rodilniku s prislovnim pomenom izhodiščno mesto ( *nesti, jiti vody 'nesti, iti iz/z/od vode'), neprehodni glagol stanja pa s samostalnikom (s »prostorskim« slovarski pomenom) v mestniku s prislov-

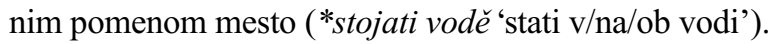

${ }^{12}$ Glagolska vezljivost je v sintetičnem pristopu, katerega izhodišče je pomen in cilj oblika, opredeljena kot lastnost glagola, da glede na svoj pomen nase veže določeno število udeležencev (aktantov): »Izhodišče vezljivosti je v pomenu, rezultat za v obliki/izrazu« (Križaj Ortar 1989: 129).

${ }^{13}$ Miklosich 1883: 263-264; Tesnière 1959: 239-258; Toporišič 2000: 353-358, 575586; Žele 2001: 243-253.

${ }^{14} \mathrm{~V}$ strokovni literaturi se pojavljajo še nevezljivi glagoli (frc. les verbes avalents) (Tesnière 1959: 239), ki pa imajo z oblikovnega vidika osebek izražen z glagolsko končnico.

${ }^{15} \mathrm{O}$ prvotnih pomenih sklonov ( $\mathrm{v}$ indoevropskih in predvsem) $\mathrm{v}$ slovanskih jezikih prim. na primer Delbrück 1893: 393-394; Meier - Brügger 2010: 398-411; Miklosich 1883: 344762; Vondrák 1928: 226-228; Граматика 1993: 455-466; Šekli 2013. 


\subsubsection{Predponsko-predložno obdobje jezika}

V predponsko-predložnem obdobju jezika so iz prostorskih/krajevnih prislovov (*vъn 'noter, notri', *na 'gor, gori', *jbz/*vy 'ven', *sb 'dol, doli', *ot(b) 'stran, proč', *ob(b/b) 'blizu'), ki so se zaradi natančnejše prostorske/krajevne pomenske določitve le-teh postavljali pred glagol ali pred samostalnik (ali tudi pred oba), nastale glagolske predpone in predlogi oziroma sestavljeni glagoli in predložni skloni. Glagolske predpone in predlogi so prvotno torej imeli prostorski/krajevni pomen (*(vb)nesti, (vbn)iti (vb) vodo 'nesti, iti v vodo', *(na)nesti, *(na)jiti (na) vodo 'nesti, iti na vodo', *(jbz)nesti, (jbz)iti (jbz) vody 'nesti, iti iz vode', *(otb)nesti, (otz)iti (otb) vody 'nesti, iti od vode', *(ob)stojati (ob) vodě 'stati ob vodi') in so s slabljenjem, šibljenjem slednjega lahko pridobivali abstraktnejši pomen (glagolske predpone vrsto glagolskega dejanja) ali celo slovnični pomen (glagolske predpone dovršnost).

Vezljivostne lastnosti nekega glagola so v predponsko-predložnem obdobju lahko torej določali: a) pomen glagolskega korena (*gr-ě- 'greti' $\rightarrow$ $* \mathrm{Sub}_{\text {nom }}-$ Verb-Sub ${ }_{\mathrm{acc}}$, *nes- 'nesti' $\rightarrow * \mathrm{Sub}_{\text {nom }}-$ Verb-Sub ${ }_{\mathrm{acc}}-$ (Praep)-Sub ${ }_{\mathrm{acc}}$ ' $*_{j i-}$ 'iti' $\rightarrow{ }^{*}$ Sub $_{\text {nom }}$-Verb-(Praep)-Sub ${ }_{\text {acc }}$ *sto- 'stati' $\rightarrow *{ }^{*}$ Sub $_{\text {nom }}$-Verb-(Praep)-Sub ${ }_{\text {loc }}$ ); b) pomen glagolske pripone, ki določa vrsto glagolskega dejanja (izkorenski stativi esivi na $*_{-} \check{e}_{l} /{ }^{\prime} a-t i *_{-} i-\check{s} i$, izkorenski stativi fientivi na $*_{-} n Q-t i *_{-} n e-s ̌ i$ ter izpridevniški in izsamostalniški stativi na $*_{-} \check{e}_{l} /{ }^{\prime} a-t i *_{-} \check{e}_{1} /$ 'a-je-š $i$ so bili neprehodni: *bbd-ě-ti 'bdeti', *lež-a-ti 'ležati', *sbx-nQ-ti 'sahniti, usihati', *zelen-ě-ti 'zeleneti', *ubož- $a$ - $t i$ 'ubožati', *kamen-ě-ti 'kameneti' $\rightarrow *$ Sub $_{\text {nom }}-$ Verb (prim. 2.1); izglagolski kavzativi in izpridevniški faktitivi na $*_{-} i-t i *_{-} i-\varsigma s i$ ter izpridevniški faktitivi na $*_{-a-t i} *_{-} a-j e-s ̌ i$ in $*_{-o v / ' e v-a-t i} *_{-u-j e-s ̌ i}$ so bili prehodni: *mor-i-ti 'moriti', *var-i-ti segrevati, kuhati', *zelen-i-ti 'zeleniti', *orvbn-a-ti 'ravnati', *rad-ov-a-ti 'radovati, veseliti' $\rightarrow * \mathrm{Sub}_{\text {nom }}-\mathrm{Verb}-\mathrm{Sub}_{\mathrm{acc}}$ (prim. 3.1.1)); c) pomen glagolske predpone (glagoli z ablativnimi predponami kot *otb-, *u-, *jbz-/*vy-, *sb- so se vezali s (prvotno brezpredložnim in drugotno predložnim) ločilniškim rodilnikom: *u-běžati 'bežati stran' $\rightarrow *{ }^{*} \mathrm{Sub}_{\text {nom }}{ }^{-}$ Praef $_{{ }_{\text {ots } / \mathrm{u} / \mathrm{jz} / \mathrm{vy} / \mathrm{ss}}}-$ Verb-(Praep)-Sub ${ }_{\mathrm{abl}}$; glagoli s predpono $*_{n a}$ - so se vezali z rodilniškim rodilnikom: *na-pblniti 'napolniti' $\left.\rightarrow *{ }^{*} \mathrm{Sub}_{\mathrm{nom}}-\operatorname{Praef}_{\mathrm{na}}-\mathrm{Verb}-\mathrm{Sub}_{\mathrm{gen}}\right)$.

\subsubsection{Glagolska vezljivost $\mathrm{v}$ primerjalnem in zgodovinskem jezikoslovju}

Primerjalno jezikoslovje na področju glagolske vezljivosti rekonstruira prvotno glagolsko vezljivost posameznih glagolov v prajeziku, zgodovinsko jezikoslovje posameznega jezika pa ugotavlja njeno spreminjanje od prajezika do različnih časovnih različic tega jezika. V nadaljevanju je glagolska vezljivost, in sicer predvsem glagolska vezava, obravnavana pri glagolih, ki se pojavljajo v jeziku Brižinskih spomenikov (dalje BS), ki so bili zapisani v obdobju 972-1039, najverjetneje že v 10. stoletju, in predstavljajo najstarejšo dokumentirano časovno različico slovenščine. Izdelana je vezljivostna tipologija glagolov: glagoli so razdeljeni na enovezljive, dvovezljive in 
trovezljive, znotraj pa še na podtipe glede na to, s katerimi skloni se vežejo. ${ }^{16}$ Stanje $\mathrm{v}$ jeziku Brižinskih spomenikov (10. stoletje) je primerjano s stanjem v stari cerkveni slovanščini (9. stoletje) in predvsem na osnovi slednjega rekonstruiranim praslovanskim stanjem. Ugotovljene so inovacije na časovni osi praslovanščina - slovenščina 10. stoletja. ${ }^{17}$

\section{Enovezljivi (monovalentni) glagoli}

Enovezljivi (monovalentni) glagoli so neprehodni (intranzitivni) (verba intransitiva) in imajo osebkov imenovalnik, nepolnopomenski glagoli pa še (pridevniški ali samostalniški) povedkov imenovalnik: $\mathbf{S u b}_{\text {nom }}-\mathbf{V e r b}_{\text {intr }}\left(-\mathbf{A d i}_{\text {nom }} / \mathbf{S u b}_{\text {nom }}\right.$ ). Polnopomenski neprehodni glagoli so nekateri glagoli stanja, nekateri nesestavljeni glagoli premikanja in nekateri glagoli nepremikanja, nepolnopomenski neprehodni glagoli pa glagoli s pomenoma *'biti' in *'postati'.

\subsection{Neprehodni glagoli stanja}

Neprehodni glagoli stanja imajo osebkov imenovalnik s pomenom nosilec/nosilnik stanja. To so: a) nekateri primarni glagoli (*byti ipf. 'biti, obstajati, nahajati se', *žiti ipf. 'živeti', *stradati ipf. 'trpeti'); b) nekateri izkorenski glagoli na $*_{-} \check{e}_{l} /$ 'a- $t i$ $*_{-} i-s ̌ i$ (III/2), tj. prvotni stanjski glagoli s pomenom doseženo stanje (stativi esivi) ( ${ }^{*} b b d-\check{e}-t i * b b d-i-\check{s} i$ ipf. 'bdeti', *lež- $a-t i * l e \check{-}-i-\check{s} i$ ipf. 'ležati'); c) nekateri izkorenski glagoli na $*_{-n Q-t i} *_{-n e-s ̌ i}$ (II), tj. prvotni stanjski glagoli s pomenom prehajanje

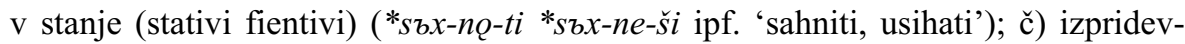
niški glagoli na $*_{-} \check{e}_{l} / ' a-t i *_{-} \check{e}_{l} / ' a-j e-\check{s} i$ (III/1), tj. stanjski glagoli (stativi) s pome-

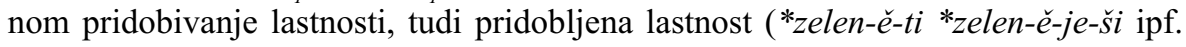

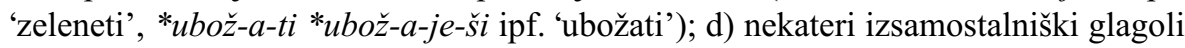
na $*_{-} \check{e}_{l} / ' a-t i *_{-} \check{e}_{l} /$ a-je-šs (III/1), tj. stanjski glagoli (stativi) s pomenom pridobivanje istovetnosti (*kamen-ě-ti *kemen-ě-je-ši ipf. 'kameneti').

V BS se pojavljajo primarni glagoli stanja *by-ti ipf. 'biti, obstajati, nahajati se' (> stcsl. выти ipf. 'biti, obstajati, nahajati se') kot polnopomenski glagol (BS na zem zuete beufi (I 8) = na sem světě běvši 'potem ko sem bil na tem svetu'), *ži-ti ipf. 'živeti' (> stcsl. жити ipf. 'živeti') (BS v ueki gemu be fiti (II 2-3), u vueki gemu be fiti (II 6-7) =v věki jemu bě žiti 'na veke bi mu bilo živeti') in *strad-a-ti ipf. 'trpeti' (> stcsl. страдати ipf. 'trpeti') (BS preife naffi zefztoco ftradacho (II 97-98)

${ }^{16}$ Delitev glagola glede na vezljivostne lastnosti, ki pogojujejo stavčne vzorce, se opira na spoznanja v Tesnière 1959: 238-282; MČ 3: 170-232; AGČJ: 592-649; Toporišič 1982; Dular 1983/84; Pogorelec 1981/1982; Toporišič 2000: 628-635; Žele 2001: 243-253.

${ }^{17}$ Rekonstrukcija praslovanskega stanja na osnovi najstarejšega slovanskega dokumentiranega gradiva (predvsem (stare) cerkvene slovanščine) se opira na spoznanja v klasičnih delih s področja primerjalne skladnje, predvsem v Miklosich 1883: 344-762 in Vondrák 1928: 226-228. 
= prějše naši žestoko stradaxQ 'prejšnji naši so hudo trpeli') ter prvotni stativi esivi *bbd-ё-ti ipf. 'bedeti' (> stcsl. въа tти ipf. 'bedeti') (BS zpe ili bde (III 32) = spe ili bde 'spe ali bde'), *sъp-a-ti ipf. 'spati' (> stcsl. съпати ipf. 'spati') (BS ili zpe ili ne zpe (I 17) = ili spe ili ne spe 'spe ali ne spe') in *sto-ja-ti ipf. 'stati' (> stcsl. стогти ipf. 'stati') (BS nu ge ftati pred ftolom bofigem (II 71-72) = nu je stati prěd stolom božjem 'in je stati pred stolom božjim', ge pred bofima ofima ftati (II 86-87) = je prěd božjima očima stati 'je pred božjimi očmi stati', da bim [...] pred tuima ofima ztoial (III 52-56) = da bim [...] prěd tvojima očima stojal 'da bi pred tvojimi očmi stal'). Ob neprehodnih glagolih stanja se lahko pojavlja neobvezno družljivo prislovno določilo prostora/kraja s pomenom mesto (lokativni pomen): $\mathbf{S u b}_{\text {nom }}-\mathbf{V e r b}_{\text {statīs }}\left(-\mathbf{A d v}_{\text {loci }}\right.$ ) (BS na sem světě, prěd stolom božjem, prěd božjima očima, prěd tvojima očima).

\subsection{Neprehodni glagoli premikanja}

Neprehodni glagoli premikanja imajo podobno kot neprehodni glagoli nepremikanja osebkov imenovalnik s pomenom vršilec/vršilnik dejanja. Sem spadajo nekateri primarni glagoli ter njihovi drugotni nedovršniki (sekundarni imperfektivi) na $*_{-a-t i} *_{-} a-j e-s ̌ i(\mathrm{~V})$ in ponavljalni glagoli (iterativi) na $*_{-} i-t i *_{-} i-s ̌ i(\mathrm{IV})\left(*_{j i-t i}\right.$ ipf. /pf. 'iti' / *po-ji-ti pf. 'iti, kreniti', *xod-i-ti ipf. 'hoditi, iti peš', *gręd-ti > *grę$s t i$ ipf. 'iti', *bred-ti $>$ *bresti ipf. 'bresti' / *brod-i-ti ipf. iter. 'broditi', *lěz-ti > *lěsti ipf. 'lesti, plaziti se' / *laz-i-ti ipf. iter. 'laziti', *plu-ti ipf. 'pluti, plavati', *pĺbv-a-ti ipf. 'pljuvati', *spě-ti ipf. 'uspevati, napredovati, hiteti', *let-ě-ti ipf. 'leteti', *stop-i-ti pf. 'stopiti' / *stop-a-ti ipf. 'stopati', *sěd-ti > *sěsti pf. 'sesti' / *sěd-a-ti ipf. 'sedati', *leg-ti > *leti pf. 'leči' / *lěg-a-ti ipf. 'legati', *tek-ti> *teti ipf. 'teči' / *těk-a-ti ipf. iter. 'tekati', *skoč-i-ti pf. 'skočiti' / *skak-a-ti ipf. 'skakati').

Neprehodni glagoli premikanja v BS so *ji-ti ipf./pf. 'iti, kreniti' / *po-ji-ti pf. 'iti, kreniti' (> stcsl. ити ipf./pf. 'iti' / по-ити pf. 'iti, kreniti') (BS iti fe na on zuet (I 8-9) = iti že na on svět 'iti pa na oni svet', na narod zlovuezki ftrazti i petzali boido ne i moki $i$ [...] zemirt (II 11-14) = na narod člověčki strasti $i$ pečali pojdo [i ne]moti i [...] s(a)mrt 'na rod človeški strasti in skrbi so šle in bolezni in smrt') $\mathrm{s}$ sestavljenko *pri-ji-ti pf. 'priti' (> stcsl. прити pf. 'priti') (BS ti pride ze nebeze (I 27) = ti pride s(a) nebese 'ti si prišel z nebes', pridete otza mega izvuolieni (I 33) = priděte, otca méga izvoĺeni 'pridite, očeta mojega izvoljeni', pride〕 zodit siuuim $i$ mrtuim (III 56-58) = prideš sQdit živim i mrtvim 'prišel boš sodit živimi in mrtvim', na zi zuu\& priti (III 68-69) = na si svět priti 'na ta svet priti') ter *vb-sta-ti pf. 'vstati' (> stcsl. въ-стати pf. 'vstati, nastati') (BS paki fe uztati na zodni den (I 9) = paki že vstati na sodni dan 'potem pa vstati na sodni dan'). Neprehodni glagoli premikanja imajo lahko neobvezno družljivo prislovno določilo prostora/ kraja s pomenoma ciljno mesto (direktivni pomen) ali izhodiščno mesto (ablativni pomen): $\mathbf{S u b}_{\text {nom }}-\mathbf{V e r b}_{\text {movendi }}\left(-\mathbf{A d v}_{\text {directionis/originis }}\right.$ ) (BS na on svět, na narod člověčki, na si svět; s(a) nebese). 


\subsection{Neprehodni glagoli nepremikanja (prizadevanja in proizvajanja)}

Neprehodni glagoli nepremikanja (prizadevanja in proizvajanja) imajo podobno kot neprehodni glagoli premikanja osebkov imenovalnik v pomenu vršilec/vršilnik dejanja. Glagoli nepremikanja brez predmeta so nekateri izsamostalniški glagoli, izpelja-

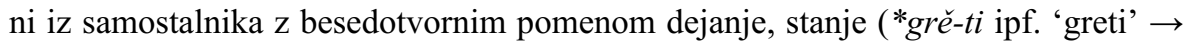
*grě- $x-b$ 'da greje, kar greje; greh' $\rightarrow$ *grě-š-i-ti ipf. 'grešiti'), in sicer nesestavljeni ali sestavljeni s predpono, ki neprehodni glagol ne spremeni v prehodni. ${ }^{18}$

V BS se pojavlja sestavljeni izsamostalniški glagol *sb-grěš-i-ti pf. 'zagrešiti' (> stcsl. съ-грtшшити pf. 'zagrešiti') (BS ecce bi detd nas ne zegrefil (II 1-2) = éte bi děd naš ne sagrěšil 'če bi ded naš ne zagrešil').

\subsection{Nepolnopomenski neprehodni glagoli}

Nepolnopomenski neprehodni glagoli so glagoli s pomenoma *'biti’ in *'postati’. V slovanskih jezikih so prvotno nastali s slabljenjem pomena polnopomenskega glagola *byti ipf. 'biti, obstajati, nahajati se'. Osebkov imenovalnik je samostalnik, povedkov imenovalnik (ali povedkov orodnik) pa je pridevnik ali samostalnik: Sub ${ }_{\text {nom }}^{-}$ Verb $_{\text {essendi/fiendi }}-\mathbf{A d i}_{\text {nom }} /$ Sub $_{\text {nom }}$. Glagol *'biti' ima esivni pomen (lat. esse 'biti'), tj. doseženo stanje, pridobljena lastnost, pridobljena istovetnost, ter izraža: a) lastnost ob pridevniškem imenskem imenovalniku, samostalniški osebkov imenovalnik ima pomen nosilec/nosilnik lastnosti: $\mathrm{Sub}_{\text {nom }}-\mathrm{Verb}_{\text {essendi }}-\mathrm{Adi}_{\text {nom }}$ (stcsl. ме вжаи месъттъ / ne bodi nesytъ (Supr. 41, 7) 'Ne bodi nenasiten'); b) istovetnost (identiteto) ob samostalniškem povedkovem imenovalniku, samostalniški osebkov imenovalnik ima

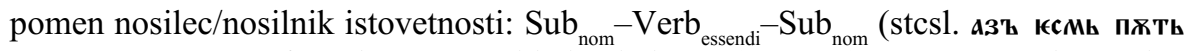
и истима и животъ / аzъ jesmь petь i istina i životъ (Jn 14, 6) 'Jaz sem pot in resnica in življenje'). Glagol *'postati' ima fientivni pomen (lat. fieri 'postati'), tj. prehajanje v stanje, pridobivanje lastnosti, pridobivanje istovetnosti, ter izraža: a) pridobivanje lastnosti ob pridevniškem povedkovem imenovalniku, osebkov imenovalnik ima pomen nosilec/nosilnik pridobivanja lastnosti: $\mathrm{Sub}_{\text {nom }}-\mathrm{Verb}_{\text {fiendi }}-\mathrm{Adi}_{\text {nom }}$ (stcsl. Aa

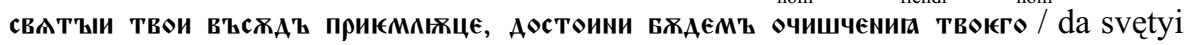
tvoi vъsǫ`ъ prijemljoce, dostoini bodemъ očiščenija tvojego (K1 3a, 12-13) 'Sveto tvoje obhajilo prijemajoč, bomo postali vredni tvojega očiščenja'); b) pridobivanje istovetnosti (identitete) ob samostalniškem povedkovem imenovalniku, osebkov imenovalnik ima pomen nosilec/nosilnik pridobivanja istovetnosti: $\mathrm{Sub}_{\text {nom }}-\mathrm{Verb}_{\text {fiendi }}-\mathrm{Sub}_{\text {nom }}$ (stcsl. педъ выстъ вода топпа / ledъ bystъ voda topla (Supr. 58, 7) 'Led je postal topla voda').

V BS se pojavlja samo nepolnopomenski neprehodni glagol *by-ti 'biti' in ima skupaj s povedkovim imenovalnikom naslednje pomene: a) lastnost (BS nizce teh del mirze ne (II 26) = ničže těx děl mrže ně 'nič ni bolj mrzko od teh del', befe priuuæ zlouиezi Uliza tazie aco fe imui gezim (II 31-33) = běše prvě člověci v lica tacije, akože

${ }^{18}$ Neprehodni glagoli nepremikanja podobno kot neprehodni glagoli premikanja (prim.

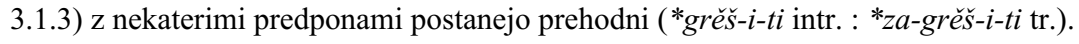


i my jesəm 'ljudje so bili prvotno v lica prav taki, kakor smo tudi mi'); b) istovetnost (identiteta) (BS efe funt dela fotonina (II 19-20) = eže sot děla Sotonina 'kot so dela Satanova', efe tatua, efe rafzboi, efe pulti ugongenige, efe roti [...], efene nauuizt (II 21-25) = ěze [jest] tatva, eže razboj, eže plti ugojenje, eže roti [...], eže nenavist 'kot je tatvina, uboj, poltenosti ugajanje, kot prisege, kot zavist', ta tri imena edin bog (III 6-7) = ta tri imena [sQt] edin bog 'ta tri imena so edini bog', naf gozbod, zueti cruz,

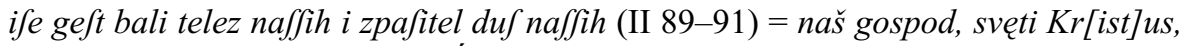
iže jest bali těles našix i spasitel duš našix 'naš gospod, sveti Kristus, ki je zdravnik teles naših in rešitelj duš naših').

\section{Dvovezljivi (bivalentni) glagoli}

Dvovezljivi (bivalentni) glagoli so prehodni (tranzitivni) (verba transitiva) ter imajo osebkov imenovalnik in (nepredložni ali predložni) odvisni sklon: $\mathbf{S u b}_{\mathbf{n o m}}-\mathbf{V e r b}_{\mathbf{t r}} \mathbf{}^{-}$ Sub ${ }_{\text {cas.obl. }}$.

\subsection{Glagoli $z$ imenovalnikom in tožilnikom oziroma nedoločnikom}

Dvovezljivi glagoli z imenovalnikom in tožilnikom oziroma nedoločnikom imajo osebkov imenovalnik in predmetni tožilnik: $\mathbf{S u b}_{\text {nom }}-\mathbf{V e r b}_{\mathbf{t r}}-\mathbf{S u b}_{\mathbf{a c c}}$. Prvotni pomen predmetnega tožilnika je prizadeto $\mathrm{v}$ širšem smislu, pri čemer je predmet $\mathrm{v}$ tožilniku (za razliko od predmeta v rodilniku, prim. 3.2) od glagolskega dejanja v celoti zaobjet. Prehodni glagoli s tožilnikom so nekateri glagoli stanja, nekateri glagoli premikanja ter nekateri glagoli nepremikanja (prizadevanja in proizvajanja). Pomeni osebkovega imenovalnika in predmetnega tožilnika so odvisni od slovarskega pomena glagola $\mathrm{V}$ povedku; tako je mogoče ločiti glagole prizadevanja in proizvajanja, premikanja in stanja ter obdobijske in naklonske glagole.

\subsubsection{Glagoli prizadevanja}

Glagoli prizadevanja imajo osebkov imenovalnik v pomenu vršilec/vršilnik dejanja, predmetni tožilnik pa v pomenu prizadeto v ožjem smislu (aficirani objekt). Večina prehodnih glagolov s tožilnikom so glagoli prizadevanja. Mednje sodijo: a) nekateri primarni glagoli ( *tep-ti ipf. 'tepsti, tolči', *pek-ti ipf. 'peči', *zbv-a-ti ipf. 'klicati'); b) vzročni glagoli (kavzativi), tj. nekateri izglagolski glagoli na $*_{-} i-t i$ *-i-ši (IV) ( *mor-i-ti *mor-i-ši ipf. 'moriti', *var-i-ti *var-i-ši ipf. 'segrevati, kuhati'); c) faktitivi, tj. nekateri izpridevniški glagoli na $*_{-} i-t i *_{-} i-s ̌ s(\mathrm{IV}), *_{-} a-t i *_{-} a-j e-s ̌ i$ (V/1), *ov/'ev-a-ti *-u-je-ši (VI) (*zelen-i-ti ipf. 'zeleniti', *orvbn-a-ti ipf. 'ravnati', *rad-ov-a-ti ipf. 'radovati, veseliti').

Slovarsko določeni glagoli prizadevanja v BS so *ob-u-ti pf. 'obuti' (> stcsl. ов-оүти pf. 'obuti') (BS bozza obuiachu (II 46-47) = bosa obujaxQ 'bosega so ubu-

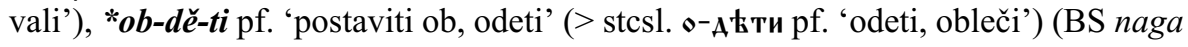


odeachu (II 47-48) = naga oděaxQ 'nagega so odevali'), *sb-grě-ti pf. 'segreti' (> stcsl. съ-грьти са pf. 'segreti se') (BS mrzna zigreahu (II 50) = mrzna sagrěaxQ 'mrzlega so ogrevali'), *tep-ti ipf. 'tepsti, tolči' (> stcsl. тети ipf. 'bičati, biti, tepsti') (BS ie tepechu (II 98-99) = ję tepěxo 'tepli so jih'), *pek-ti ipf. 'peči' (> stcsl. пєшти ipf. 'peči') (BS ie [...] petfachv (II 100) =je [...] pečaxo 'so jih pekli'), *tbn-a-ti ipf. 'cepiti, sekati, rezati' (izpeljano iz *tę-ti, 1-2sg praes. *tbn-Q *tbn-e-ši ipf. 'cepiti, sekati, rezati' > stcsl. тати тьмж тьмеши ipf. 'cepiti, sekati') (BS $i$ metfi tnachu (II 101) = i meči tnaxQ 'in z meči so jih sekali'), *orz-trzg-a-ti pf. 'raztrgati' (csl. тръгати 'trgati, puliti', stcsl. ис-тръгати 'raztrgati, strgati') (BS felezni cliufi ge raztrgachu (II 102-103) = želězni kĺuči ję raztrgaxo 'z železnimi kljukami so jih raztrgali'), *ob-klevet-a-ti > *oklevetati pf. (> stcsl. о-клєвєтати ipf./pf. 'oklevetati') (BS bratra oclevuetam (II 21) = bratra oklevetam 'brata oklevetamo'), *pri-zъv-a-ti pf. 'priklicati' (> stcsl. при-зъвати pf. 'poklicati, priklicati') (BS bofi raba prizzuaufe (II 109-110) = božj[e] rabę prizvavše 'potem ko boste poklicali božje služabnike'), *vb-zbv-a-ti pf. 'poklicati' (> stcsl. въ-зъвати pf. 'poklicati') (BS iefe vzovuef tvoimi vzti (I 32-33) = jęže vzoveš tvojimi usti 'ki jih boš poklical s svojimi usti'). V trpniku so izpričani glagoli *po-zъv-a-ti pf. 'poklicati' (> stcsl. по-зъвати pf. 'poklicati') in "po-běd-i-ti pf. 'premagati, prisiliti' (> stcsl. по-в i gezm bratria bozuuvani i bbgeni (II 66-68) = i jes(a)m, bratrija, pozvani i p[o]b[ě] jeni 'in smo, bratje, poklicani in prisiljeni'), *krbst-i-ti pf. 'krstiti' (> stcsl. крьстити pf. 'krstiti') in *u-vort-i-ti pf. 'vrniti, poslati' (> stcsl. oү-вратити pf. 'vrniti') (BS pongefe bih na zi zvuet vuuraken i bih crifken (I 12-13) = pońeže bix na si svèt [u]vraten i bix krščen 'potem ko sem bil na ta svet poslan in sem bil krščen', ponefe

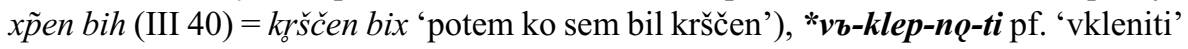
(> csl. въ-кпемхти pf. 'vkleniti') (BS uclepenih bozcekachu (II 54-55) = vklepenix posétaxQ 'vklejene so obiskovali').

Vzročna glagola v BS sta *věs-i-ti ipf. ‘vesiti' (> stcsl. в всити ipf. 'vesiti') (BS ie [...] po lezv vuefachu (II 102) = je [...] po lěsu věšaxQ 'so jih po lesu vesili') in *u-těš-i-ti pf. 'utešiti, potolažiti' / *u-těx-ja-ti > *u-těšati ipf. 'tešiti, tolažiti' (> stcsl. оү-тьшити pf. 'utešiti, pomiriti' / oү-тłшати ipf. 'tešiti, pomirjati') (BS te uteffahu (II 56) = tę utěšaxQ 'te so tešili'). ${ }^{19}$

\subsubsection{Glagoli proizvajanja}

Glagoli proizvajanja imajo osebkov imenovalnik v pomenu vršilec/vršilnik dejanja, predmetni tožilnik pa v pomenu rezultat dejanja (eficirani objekt). V primerjavi z glagoli prizadevanja so glagoli proizvajanja manj številni (*děl-a-ti ipf. 'delati', *tvor-i-ti ipf. 'delati, oblikovati', *čin-i-ti ipf. 'delati', *zbd-a-ti ipf. 'zidati', *pbs-a-ti ipf. 'pisati').

${ }^{19}$ Oblika imperfekta BS utěšaxo je lahko tvorjena tako od dovršnika *utěšiti kot od (drugotnega) nedovršnika *utěšati. Glede na to, da je vse oblike imperfekta v delu besedila, v katerem se pojavlja oblika utěšaxo, mogoče tvoriti iz dovršnika, je zelo verjetno, da je tudi oblika utěšaxo imperfekt glagola *utěšiti. 
Glagola proizvajanja v BS sta *děl-a-ti ipf. 'delati' (> stcsl. А фмати ipf. 'delati') (BS iafe oni delafe (II 43-44) = jaže oni dělaše 'katera so oni delali') in *tvor-i-ti ipf. 'delati, oblikovati' / *sb-tvor-i-ti pf. 'narediti' (> stcsl. творити ipf. 'ustvarjati, oblikovati, delati' / съ-творити pf. 'narediti') (BS ife zuori nebo i zemlo (III 10-11) = iže s[t]vori nebo i zemlq ' ki je ustvaril nebo in zemljo', efe iezem ztvoril (I 23) = ě̌e jesəm stvoril 'kar sem storil', efe iezem ztuoril zla (II 11-12) = ě̌e jesəm stvoril zla 'kar sem storil zla', efe ge na fem fzuete chifto ftuoril (II 79-81) = eže je na sem světě kiždo stvoril 'kar je na tem svetu vsakdo storil', mui [...] toie mofim ztoriti (II 104, $106-107)=m y[\ldots]$ toje možem storiti ' $\mathrm{mi}$ isto moremo storiti', efe oni [...] ftuorife (II 107-108) = eže oni [...] stvorišę 'kar so oni storili', efe iezem uuede ztuoril (III 30-31) = ě̌e jesam vědę stvoril 'kar sem vede storil', efe iefem ztuoril ptiuuo bogu (III 37-39) = eže jesam stvoril protivo bogu 'kar sem storil proti bogu'.

Glagol *tvor-i-ti/*sb-tvor-i-ti se kot nepolnopomenski glagol z oslabljenim slovarskim pomenom pojavlja tudi v fraznih glagolih: ${ }^{20} *$ trěbq (sъ)tvoriti 'delati žrtev, žrtvovati' (BS efe trebu tuorim (II 20) = eže trěbo tvorim 'ko žrtvujemo'), *jbzpovědb (sъ)tvoriti 'delati izpoved, izpovedati se' (BS da bim cifto izpouued ztuoril (III 22$23)=$ da bim čisto izpověd stvoril 'da bi se čisto izpovedal'), *milb se tvoriti 'delati se mil, prositi milosti' (BS tebe ze mil tuoriv od zih poftenih greh (I 20-21) = tebè sę mil tvoŕ od six poštenix grěx 'tebe milosti prosim za te naštete grehe', teh ze tebe mil tuoriv (I 23-24) = těx sę tebě mil tvoŕq 'za té te milosti prosim').

\subsubsection{Prehodni glagoli premikanja}

Prehodni glagoli premikanja so nesestavljeni prehodni in sestavljeni prehodni, tvorjeni iz nesestavljenih neprehodnih glagolov.

Nesestavljeni prehodni glagoli premikanja (kot na primer *nes-ti ipf. 'nesti' / *nos-i-ti ipf. iter. 'nositi', *ved-ti ipf. 'vesti' / *vod-i-ti ipf. iter. 'voditi', *vez-ti ipf. 'peljati' / *voz-i-ti ipf. iter. 'voziti', *sbl-a-ti ipf. 'pošiljati') imajo predmetni tožilnik s pomenom prizadeto in prislovni predložni tožilnik (tožilnik smeri, accusativus directionis) s pomenom ciljno mesto (direktivni pomen): $\mathbf{S u b}_{\text {nom }}-$ Verb $_{\text {movendi }}-\mathbf{S u b}_{\text {ace }}$ (-Praep-Sub ${ }_{\text {acc }}$ ).

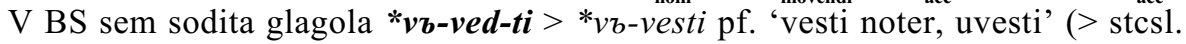
въ-вести pf. 'vesti noter, uvesti') (BS ftranna bod crovvi zuoge uvedechu (II 50-52) = stranna pod krovi svoję vveděxg 'tujca so pod krove svoje vodili') in *vb-sedl-i-ti pf. 'vseliti' (> stcsl. въ-секити pf. 'vseliti') (BS dofda ni tamoge vzedli v zezarftuo fuoge (II 61-63) = dožda ni tamoje vsedli, v cěsaŕstvo svoje 'dokler nas tja vseli, v cesarstvo svoje'). Brez tožilnika smeri se pojavlja glagol *po-stav-i-ti pf. 'postaviti' (> stcsl. по-ставити pf. 'postaviti') (BS to $n$ bozzledine balouvanige pozled ge pozftavv (II 91-93) = to n[ə] poslěd(a)né balovanje poslěd je postav [il] 'to pa poslednje zdravilo je naposled postavil').

${ }^{20} \gg[$ F]razni glagoli, v katerih se kot vez pojavljajo različni drugi glagoli, npr. vršiti ali delati, njihovo povedkovo določilo pa so izglagolski samostalniki ali medmeti« (Toporišič 2000: 612). 
Neprehodni glagoli premikanja, ki so sestavljeni s predponami kot $*_{v b}(n)$-,

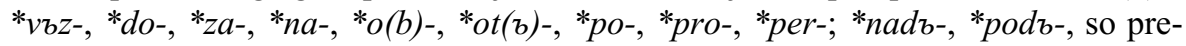
hodni. ${ }^{21}$ Za razliko od nesestavljenih prehodnih glagolov imajo ob sebi samo predmetni tožilnik s pomenom prizadeto, ne pa tudi prislovnega predložnega tožilnika s pomenom ciljno mesto: Sub $_{\text {nom }}-$ Praef-Verb $_{\text {movendi }}-\mathbf{S u b}_{\text {acc }}$ V BS se pojavlja glagol "per-stop-a-ti ipf. 'stopati preko' (> stcsl. прt-стжпати ipf. 'prestopati') (BS nu ge preftopam (II 24-25) = nu je prěstopam 'in jih prestopamo’).

\subsubsection{Prehodni glagoli stanja}

Prehodni glagoli stanja imajo osebkov imenovalnik s pomenom nosilec/nosilnik stanja in predmetni tožilnik oziroma predmetni odvisnik s pomenom prizadeto. V BS se pojavljajo stanjski glagoli na $*_{-} \check{e}_{l} /$ a-ti oziroma $*_{-} n Q-t i$, in sicer glagoli umevanja, pri čemer predmet ni vedno besedilno aktualiziran: *po-mbn-е̌-ti ipf./pf. 'spomniti se' (> stcsl. по-мькњти ipf./pf. 'spomniti se') (BS efe pomngu ili ne pomngu (I 13) = ě̌e pomń ili ne pomńQ 'kar pomnim ali ne pomnim'), *po-měn-nQ-ti se pf. 'spomniti se' (> stcsl. по-манхти/по-мымхти са pf. 'spomniti se') (BS $i$ pagi bratriia pomenem ze da i zinoune bofi narefem ze (II 14-17) = i paki, bratrija, poměněm sę, da i sinove božji narečem sę 'in vendar, bratje, spomnimo se, da se tudi sinovi božji imenujemo'), *věd-ě-ti ipf. 'vedeti' (> stcsl. вłatт ти ipf. 'vedeti, znati, poznati') (BS ili vuede ili ne vuede (I 14) = ili vědę ili ne védę 'ali vede ali ne vede', efe iezem uuede ztuoril ili neuuede (III 30, 31) = ěze jesam vědę stvoril ili ne vědę 'kar sem vede storil ali ne vede', ti edin bofe vuez caco mi iega potreba vuelica (I 20) = ti edin, bože, věs, kako mi [je] jega potrěba velika 'ti edini, o bog, veš, kako mi je njega potreba velika'). ${ }^{22}$

\subsubsection{Obdobijski in naklonski glagoli}

Obdobijski in naklonski glagoli imajo osebkov imenovalnik v pomenu vršilec/vršilnik dejanja in predmetni tožilnik oziroma nedoločnik v pomenu prizadeto: $\mathbf{S u b}_{\text {nom }}{ }^{-}$ Verb-Sub ${ }_{\text {acc }} /$ Inf.

Obdobijski (fazni) glagoli imajo polni slovarski pomen, s katerim izražajo potek glagolskega dogajanja (začetek: inhoativni/ingresivni pomen; trajanje: durativni pomen; konec: terminativni/finitivni pomen), in imajo ob sebi predmetni tožilnik ali nedoločnik. V BS se pojavlja glagol *na-čę-ti pf. 'začeti' (> stcsl. ма-чати pf. 'začeti') (BS eccẹ tage dela nafnem delati (II 42-43) = éte taje děla načnem délati 'če prav ta dela začnemo delati'), katerega pomen lahko razumemo kot slovarskega (začetek glagolskega dogajanja) ali slovničnega (prihodnost), tj. kot pomožni glagol za tvorbo opisnega prihodnjika nedovršnih glagolov.

Naklonski (modalni) glagoli imajo polni slovarski pomen, s katerim izražajo odnos do glagolskega dogajanja, in sicer zmožnost (potencialnost) (*mog-ti $>$ *moti

${ }^{21}$ Miklosich 1883: 378; Vondrák 1928: 267.

${ }^{22}$ Natančni prikaz pomenskih/udeleženskih vlog glagolov umevanja je predstavljen v Grošelj 2011. 
ipf. 'moči', *um-ě-ti ipf. 'umeti, moči', *sъm-ě-ti ipf. 'smeti'), obveznost (debitativnost) (*terb-ov-a-ti ipf. 'morati', *jbm-ě-ti ipf. 'imeti, morati'), željo (voluntativnost) (*xъt-ě-ti/*xot-ě-ti ipf. 'hoteti, želeti'). V BS se pojavljajo naslednji naklonski glagoli: *mog-ti > *moti ipf. 'moči' (> stcsl. мошти ipf. 'moči') (BS tige fe mofem i mui efte buiti (II 41-42) = tije že možem i my ešče byti 'isti pa moremo tudi mi še biti', egofe ne mofem nikīfe liza ni ucriti (II 68-70) = egože ne možem nikimže lica ni ukriti 'pred komer ne moremo z nikomer lica niti skriti', mui [...] toie mofim ztoriti (II 104, 106-107) = my [...] toje možem storiti 'mi isto moremo storiti'), *rač-i-ti ipf. 'hoteti, blagovoliti' (> stcsl. рачити ipf. 'hoteti, želeti, blagovoliti') (BS da mi rafite na pomoki biti (III 20-21) = da mi račite na pomoti biti 'da mi hočete na pomoči biti', crifte bofi zinu ife iezi razil na zi zuu\& priti (III 67-69) = Kriste, božji simu, iže jesi račil na si svět priti 'o Kristus, božji sin, ki si hotel na ta svet priti'), *xot-ě-ti ipf. 'hoteti'

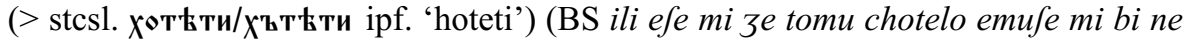
doztalo choteti (I 16-17) = ili eže mi sę tomu xotělo, emuže mi bi ne dostalo xotěti 'ali ker se mi je hotelo to, kar se mi ne bi smelo hoteti', i rad ze chocu caiati (III 47-48) $=i$ rad sę xoto kajati 'in rad se hočem kesati').

\subsection{Glagoli $\mathrm{z}$ imenovalnikom in rodilniškim rodilnikom ${ }^{23}$}

Dvovezljivi glagoli z imenovalnikom in rodilniškim rodilnikom (tj. kontinuantom praindoevropskega rodilnika) imajo osebkov imenovalnik s pomenom vršilec/vršilnik dejanja in predmetni rodilnik s pomenom prizadeto: $\mathbf{S u b}_{\text {nom }}-\mathbf{V e r b}_{-} \mathbf{S u b}_{\text {gen }}$. Prvotni pomen rodilniškega rodilnika je bil delnost (partitivni pomen) (to je delni rodilnik, genitivus partitivus), predmet $\mathrm{v}$ rodilniku (za razliko od predmeta v tožilniku, prim. 3.1) od glagolskega dejanja ni v celoti zaobjet. Glagoli s predmetnim rodilniškim rodilnikom so bili prvotno:

a) glagoli s pomeni kot*‘jesti’, *'piti', *'pokusiti’, *‘(za)užiti’, prvotno s partitivnim pomenom v smislu *`jesti, piti, pokusiti, (za)užiti od česa' (*jěd-ti > *jěsti ipf. 'jesti'; *pi-ti ipf. 'piti'; *(vb-)kus-i-ti pf. 'pokusiti' / *(vb-)kus-ja-ti $>*(v b-) k u s ̌ a t i$ ipf. 'pokušati');

b) glagoli s pomeni kot *'imeti', *'prejeti, dobiti', prvotno s partitivnim pomenom v smislu *'imeti, prejeti, dobiti od česa' (*jbm-ě-ti ipf. 'imeti'; *pri-ję-ti pf. 'prejeti, dobiti' / *pri-jbm-a-ti ipf. 'prejemati, dobivati', *po-luč-i-ti pf. 'prejeti' / *po-luč- $a$ - $t i$ ipf. 'prejemati');

c) glagoli čutnega zaznavanja s pomeni kot *'slišati', *'videti' (*slyš-a-ti ipf. 'slišati', *sluš-a-ti ipf. 'slišati, poslušati', *vъn-ǔ́-i-ti pf. 'zaslišati'; *vid-ě-ti ipf. 'videti, gledati', *zbr-ě-ti ipf. 'videti, gledati' / *do-zbr-ě-ti pf. 'uzreti', *motr-i-ti ipf. 'gledati', *ględ-a-ti/*ględ-ě-ti ipf. 'gledati');

${ }^{23}$ Praindoevropski rodilnik se v praslovanščini oblikovno ni ohranil; praslovanski rodilnik oblikovno nadaljuje praindoevropski ločilnik, pomensko pa praindoevropski ločilnik in rodilnik. Tisti praslovanski rodilnik, ki pomensko nadaljuje praindoevropski rodilnik, je v pričujočem besedilu imenovan rodilnilniški rodilnik, tisti pa, ki pomensko nadaljuje praindoevropski ločilnik, pa ločilniški rodilnik. 
č) glagoli duševnega zaznavanja s pomeni kot *'razumeti', *'paziti, opazovati, varovati, čuvati', *'obiskati' (*orzum-ě-ti pf./ipf. 'razumeti' / *orzum-ě-va-ti ipf. 'razumevati'; *bĺud-ti > *blusti ipf. 'paziti, opazovati', *vъn-ę-ti pf. 'opaziti' / *vъn-bm-a-ti ipf. 'opazovati', *pas-ti ipf. 'varovati, čuvati’; *po-sět-i-ti pf. 'obiskati' / *po-sět-ja-ti > *po-sětati ipf. 'obiskovati');

d) glagoli s pomeni kot *'doseči, zgrabiti, dotakniti se', *'oprijeti se, držati se', *'slediti', ki so bili večinoma povratni s *sę (*(pri-)kos-nQ-ti sę pf. 'dotakniti se' / *(pri-)kas-a-ti sę ipf. 'dotikati se', *tъk-no-ti pf. 'dotakniti se' / *tyk-a-ti ipf. 'dotikati se'; *(j)ę-ti pf. 'oprijeti se, zgrabiti', *dbrž-a-ti (se) ipf. 'držati se'; *seld-i-ti ipf. / *seld-ov-a-ti ipf. 'slediti');

e) glagoli premikanja s predpono *do-s prvotnim adlativnim pomenom *'iti do' (*do-jiti pf. 'doiti, dospeti, priti, prispeti', *do-tek-ti $>*$ do-teti pf. 'dospeti, dohiteti', *do-plu-ti pf. 'dopluti, pripluti', *do-ved-ti $>* d o$-vesti pf. 'dovesti, privesti');

f) glagolidoseganja s prenesenimi pomeni kot*'hoteti, želeti, iskati, zahtevati', *'biti lačen, biti žejen', *'prositi', *‘čakati', *'ljubiti', *'sovražiti' (*xъt-ě-ti/*xot-ě-ti ipf. 'hoteti', *žel-ě-ti/*žel-a-ti ipf. 'želeti si', *(j)isk-a-ti ipf. 'iskati'; *olk-a-ti 'biti lačen', *žęd-ě-ti/*žęd-a-ti 'biti žejen'; *pros-i-ti ipf. 'prositi’; *ča-ja-ti ipf. ‘čakati', *žbd-a-ti ipf. ‘čakati’; *lubb-i-ti ipf. 'ljubiti' / *vbz-lubb-i-ti pf. 'vzljubiti’; *ne-na-vid-ě-ti ipf. 'sovražiti' / *vbz-ne-na-vid-ě-ti pf. 'zasovražiti').

V slovanskih jezikih je opazno spreminjanje glagolske vezave od rodilnika k tožilniku: Sub nom $_{-V e r b-S u b} \rightarrow$ Sub $_{\text {nom }}-$ Verb-Sub $_{\text {acc }}$. V BS je predmetni rodilniški rodilnik ohranjen redko, v večini primerov se že pojavlja predmetni tožilnik.

Predmetni rodilniški rodilnik je ohranjen pri glagolih *po-sět-i-ti pf. 'obiskati' / *po-sět-ja-ti > *po-sětati ipf. 'obiskovati' (> stcsl. по-сьтити pf. 'obiskati' / по-сћштати ipf. 'obiskovati': гако посьти господь вогъ пюдии своихъ / jako posěti gospodь bogъ ljudii svoixъ (Lk 7, 16) 'kajti gospod bog je obiskal svoje ljudi') (BS malomogoncka [...] bozzekacho (II 48-49) = malomoget́a [...] posétaxQ 'onemoglega so obiskovali', uclepenih bozcekachu (II 54-55) = vklepenix posétaxo 'vklejene so obiskovali') ${ }^{24}$ in *jisk-a-ti ipf. 'iskati' (> stcsl. искати ipf. 'iskati': искаашє подовьма врtвменє / iskaaše podobьna vrěmene (Lk 22, 6) 'Iskal je ugoden čas') (BS tofe izco iega milozti (III 11-12) = tože isko jega milosti 'tudi iščem njegovo milost').

Predmetni rodilniški rodilnik je bil zamenjan s predmetnim tožilnikom pri nasle-

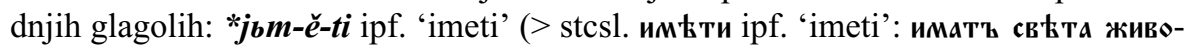
тьNaiero / imatı světa životınajego (Jn 8, 12) 'Ima življenjsko luč') (BS imeti mi ie fivuot po zem imeti mi ie otpuztic moih grechou (I 9-10) = iměti mi je život po sem, iméti mi je otpustak mojix grěxov 'imeti mi je življenje po tem, imeti mi je odpustek mojih grehov', zio prio imeti (II 87) = sjo prjo iměti 'ta spor imeti', elicofe zimizla imam (III 48-49) = elikože s(a)misla imam 'kolikor smisla imam'), *pri-ję-ti pf.

${ }^{24}$ Oblika BS malomoget́a kaže tako na rodilnik kot na tožilnik (nastanek kategorije živosti pri samostalnikih moškega spola), medtem ko oblika BS vklepenix nedvomno kaže na rodilnik. 
'prijeti' / *pri-jem-a-ti ipf. 'prijemati' (> stcsl. при-юати pf. 'prijeti, prejeti': подовьно кстъ квасоу, кГоже приємъши жена съкръ въ мжцћ / podobьno jestъ kvasu, jegože prijemъši žena sъkry vъ mocě $(L k 3,21)$ 'Podobno je kvasu, ki ga je žena, potem ko ga je dobila, skrila v moki') (BS primi moiv izpovued moih grechou (I 11) = primi mojo izpověd mojix grěxov 'primi mojo izpoved mojih grehov', primete vuecfne vuezelie $i$ vuecfni fiuot (I 33-34) = priměte věčně veselje $i$ věčni život 'prejmite večno veselje in večno življenje', da bim [...] puztic ot boga priel (III 22-34) = da bim [...] otpustək od boga prijęl 'da bi odpustek od boga prejel', ${ }^{25}$ *slišs-a-ti ipf. 'slišati' / *u-sliš-a-ti pf. 'zaslišati' (> stcsl. слышати ipf. 'slišati' / or-слышати pf. 'zaslišati': сваттыихъ сповесъ аа спъшимъ / svętyiхъ slovesъ da slyšimъ (Supr. 452, 26) 'Da slišimo svete besede') (BS da bim uzliffal na zodni den tuo milozt vueliu (I 31-32) = da bim uslišal na sQdni dan tvo milost veĺ 'da bi uslišal na sodni dan tvojo milost veliko'), *ne-na-vid-ě-ti ipf. 'sovražiti' / *vbz-ne-na-vid-ě-ti pf. 'zasovražiti' (> stcsl. мє-ма-видћти ipf. 'sovražiti' / въз-мє-ма-виАћти pf. 'zasovražiti': мє можетъ миръ менавид tти васъ, мемє же мемавидитъ / ne možetъ mirъ nenaviděti vasъ, mene že nenaviditъ (Jn 7,7) 'Ne more svet sovražiti vas, mene pa sovraži') (BS nepriiaznina uznenauvideffe (II 32-33) = [děla] Neprijaznina vznenaviděšę 'dela Neprijaznega so zasovražili'), *ĺub-i-ti ipf. 'ljubiti' / *vbz-ĺub-i-ti pf. 'vzljubiti' (> stcsl. пювити ipf. 'ljubiti' / въз-лювити ipf. 'vzljubiti’: омо, кегже мъ пювимъ / ono, jegože my ljubimъ (Supr. 130, 1) 'Ono, kar mi ljubimo’) (BS bofiu uzliubife (II 34) = [děla] božj[a] vzlubišę 'dela božja so vzljubili').

Ob zanikanem glagolu in posledično s predmetom v rodilniku, ki je za določanje glagolske vezave nepoveden, se pojavljata glagola *pas-ti ipf. 'varovati, čuvati' (> stcsl. пасти ipf. 'pasti') (BS efe roti choife ih ne pazem (II 23-24) = eže roti, kojixže ne pasem 'kakor prisege, ki jih ne spoštujemo') in “sb-pas-a-ti ipf. 'varovati' (> stcsl. съ-пасати ipf. 'reševati, varovati, ščititi') (BS iezem ne zpazal nedela (I 18) = jesəm ne spasal neděla 'nisem spoštoval praznika').

Predmetni sklon ni besedilno aktualiziran pri naslednjih glagolih: *pi-ti ipf. 'piti' (> stcsl. пити ipf./pf. 'piti') (BS zefti ich pigem (II 37-38) = časti jix pijem 'na njihovo čast pijemo'); ${ }^{26}$ *vid-ě-ti ipf. 'videti' (> stcsl. видњти ipf. 'videti': вижаь и вимограда свокго / viždь i vinograda svojego (Euch 100a 1) 'Poglej tudi svoj vinograd') in *orzиm-ё-ti 'razumeti' (> stcsl. разоүмњти pf./ipf. 'razumeti': разоүмњвъши свокго зъла / razuměvъši svojego zъla (Supr. 43, 23) 'razumevši svoje zlo') (BS mofete potomu zinzi uvideti i zami razumeti (II 27-29) = možete potomu, sinci, vidéti i sami razuměti 'morete zato, sinčki, videti in sami razumeti').

${ }^{25} \mathrm{Ob}$ zanikanem glagolu se pojavlja rodilnik (BS nikoligefe petfali ne imugi ni flzna teleze imoki (II 4-6) = nikoliježe pečali ne imy ni slznna tělese imoti 'nikoli skrbi ne imajoč niti solznega telesa imajoč', starofti ne prigemlioki (II 3-4) = starosti ne prijemloti 'starosti ne prijemajoč').

${ }^{26}$ Pri dajalnik BS čəsti gre za prislovni dajalnik, in sicer dajalnik namena (dativus finalis), katerega pomen je pogojen s pomenom glagola (glagol prizadevanja) in pomenom samostalnika (pojem). 


\subsection{Glagoli z imenovalnikom in ločilniškim rodilnikom}

Ločilniški rodilnik ( $\mathrm{tj}$. pomenski kontinuant praindoevropskega ločilnika) ima prvotno prislovni pomen izhodiščno mesto (ablativni pomen), drugotno pa tudi predmetni pomen prizadeto: $\mathbf{S u b}_{\text {nom }}-\mathbf{V e r b}-\mathbf{S u b}_{\mathbf{a b l}}$. Ločilniški rodilnik imajo prvotno:

a) glagoli premikanja s predponami *ot(b)- 'od-', *u- 'stran', *jbz-/*vy- 'iz-', ${ }^{*} s b^{-}$'z-/s-' s prvotnim ablativnim pomenom *'iti od' (*ot-i-ti pf. 'iti od, oditi',

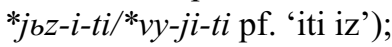

b) glagoli s pomeni *'bežati', *uumakniti se, izogibati se, paziti se, varovati se', *'opustiti, odstopiti, odpovedati se', *'zgrešiti, zamuditi' ( *běž-a-ti ipf. 'bežati' / *u-běž-a-ti pf. 'ubežati’; *klon-i-ti ipf. 'izogibati se'; *ot-sta-ti > *ostati pf. 'opustiti', *po-stop-i-ti pf. 'odstopiti'; *grěš-i-ti ipf. 'grešiti');

c) glagoli s pomeni *'biti prazen, pogrešati, potrebovati' ( *terb-ov-a-ti ipf. 'potrebovati');

c) glagoli s pomeni kot *'bati se', *'osupniti, ustrašiti se', *'sramovati se', *‘čutiti gnus, imeti odpor, mržnjo' (*boj-a-ti sę ipf. 'bati se', *trepet-a-ti ipf. 'trepetati, tresti se; *užas-nQ-ti sę pf. 'osupniti' / *užas-a-ti sę ipf. 'osupljati', *u-straš-i-ti se pf. 'ustrašiti se' / *u-straš-a-ti sę ipf. 'ustrahovati se'; *styd-ě-ti sę ipf. 'sramovati se', *sorm-i-ti sę pf. / *sorm-ja-ti sę> *sormĺati sę *ipf. 'sramovati se'; *gnus-i-ti sę ipf. / *gnus-ja-ti sę> *gnušati sę ipf. 'čutiti gnus, stud', *mbrz-ě-ti sę ipf. 'imeti mržnjo');

d) glagoli s pomeni čustvenega vznemirjenja kot * ‘jokati, objokovati’, *‘žalovati, obžalovati', *'maščevati se, kaznovati' ( *plak-a-ti ipf. 'jokati'; *žal-i-ti ipf. 'žalovati, obžalovati'; *mbst-i-ti pf. 'maščevati se, kaznovati').

V slovanskih jezikih je opazno spreminjanje glagolske vezave glagolov z brezpredložnim ločilniškim rodilnikom, in sicer glede na to, ali se je ločilnik pojavljal ob glagolih premikanja ali nepremikanja.

Prislovni brezpredložni ločilnik ob glagolih premikanja s pomenom izhodiščno mesto se je navadno zamenjal s predložnim prislovnim ločilnikom z istim pomenom: Sub $_{\text {nom }}-$ Verb $_{\text {+movendi }^{-}}-$Sub $_{\text {abl }} \rightarrow$ Sub $_{\text {nom }}-$ Verb $_{\text {+movendi }}-$ Praep-Sub $_{\text {abl }}$ (Praep $=*^{*}$ otb, $\left.*_{j b z}, *_{s b}\right)$. V BS pri enem pojavljajočem se tovrstnem glagolu prislovni ločilnik besedilno ni aktualiziran: *běž-a-ti ipf. 'bežati' / *u-bе̌̌̆-a-ti pf. 'ubežati' (> stcsl. вњжати ipf. 'bežati' / or-въжати pf. 'ubežati': микътоже овьштакго көньца оүвŁжа / nikъtože obьštajego konьca uběža (Supr. 238, 10) 'Nihče ni ubežal skupnemu koncu') (BS nicacofé ubegati (II 70-71) = nikakože uběgati 'nikakor ubežati').

Predmetni brezpredložni ločilnik ob glagolih nepremikanja se je lahko zamenjal s predmetnim brezpredložnim tožilnikom: $\mathbf{S u b}_{\text {nom }}-$ Verb $_{\text {-movendi }}-\mathbf{S u b}_{\text {abl }} \rightarrow \mathbf{S u b}_{\text {nom }}$ -Verb -movendi - Sub $_{\text {acc }}$. V BS je predmetni ločilnik ohranjen pri glagolih *ot-sta-ti $>$ *ostati pf. 'opustiti' (> stcsl. --стати pf. 'ostati; pustiti (pri miru); oditi, opustiti', --стати с⿱ pf. 'odreči se čemu') (BS botomu ozftanem zich mirzcih del (II 17-19) = potomu ostaněm six mrzkix děl 'zato opustimo ta mrzka dela'), *u-kry-ti pf. 'skriti'

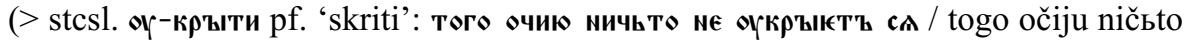
ne ukryjetъ sę 'Pred tega očmi se nihče ne bo skril') (BS egofe ne mofem nikīfe liza 
ni ucriti (II 68-70) = egože ne možem nikimže lica ni ukriti 'česar ne moremo pred nikomer lica niti skriti') in *ka-ja-ti se ipf. 'kesati se' (> stcsl. кагати са ipf. 'kesati se': кақ са вьсека зъловъ, вже сътворих' 'Kesam se vse zlobe, ki sem jo storil') (BS caiu ze moih grechou (III 46-47) = kajo se mojix grěxov 'kesam se svojih grehov'), medtem ko je bil zamenjan s predmetnim tožilnikom pri glagolu *po-ščed-ěe-ti pf. 'obvarovati, prihraniti, prizanesti' (> stcsl. по-штад қти pf. 'privarčevati, prihraniti, prizanesti': поштади оүАөвъ своихъ / poštędi udovъ svoixъ 'Prizanesi udom svojim') (BS eche me bofe poftedifi (III 50) = ete mę, bože, poščędiši 'če me boš, o bog, prihranil').

\subsection{Glagoli $\mathrm{z}$ imenovalnikom in dajalnikom}

Dajalnik ima prvotno predmetni pomen prejemnika (recipiens) oziroma lastnika (possessor) ali prislovni pomen namena (finis): $\mathbf{S u b}_{\text {nom }}-\mathbf{V e r b}-\mathbf{S u b}_{\mathrm{dat}}$. Glagoli z dajalnikom so bili prvotno:

a) nekateri glagoli rekanja s pomeni kot*'moliti', *'lagati', *'soditi' (*modl-i-ti (se) ipf. 'moliti'; *lbg-a-ti ipf. 'lagati'; *soditi ipf. 'soditi');

b) glagoli s pomenom *'vladati' (*vold-ti > *volsti ipf. 'vladati'); ${ }^{27}$

c) glagoli koristi in škode s pomeni kot *'pomagati', *'služiti', *'ubogati, kloniti, pokoriti se, podvreči se', *'žrtvovati', *'paziti, varovati', *'koristiti', *'škoditi' (*po-mog-ti > *po-moti pf. 'pomoči' / *po-mag-a-ti ipf. 'pomagati'; *služ-i-ti ipf. 'služiti' / *po-služ-i-ti pf. 'služiti'; *povin-ov-a-ti sę ipf. 'podvreči se', *po-kor-i-ti sę pf. 'pokoriti se', *klon-i-ti sę pf. 'kloniti se' / *klan-ja-ti sę > *klańati sę ipf. 'klanjati se', *po-klon-i-ti sę pf. 'prikloniti se'; *po-žer-ti pf. ‘žrtvovati'; *vъn-im-a-ti sebě ipf. 'paziti, varovati se', *orzum-ě-ti ipf. 'razumeti'; *polbza byti 'biti korist', *pro-spě-ti ipf. 'koristiti', *bolg-o-dě-ja-ti ipf./pf. 'delati dobro'; *verd-i-ti pf. 'škodovati', *(škod)-i-ti ipf./pf. 'škoditi’, *vbz-born-i-ti ipf. 'braniti, preprečiti', *za-pę-ti pf. 'spodmakniti noge', *za-dě-va-ti ipf. 'preprečiti');

č) glagoli s pomeni kot *'delati prikladno, primerno; podobno; enako’ v tvorniku ter *'biti prikladno, primerno; podobno; enako' v trpniku ( dobiti se', *do-sto-ja-ti ipf. 'spodobiti se', *god-i-ti ipf. 'biti prijetno, prikladno, po godu', *god-ě byti 'biti po godu').

V slovanskih jezikih je ponekod opazno spreminjanje glagolske vezave od dajalnika k tožilniku: Sub ${ }_{\text {nom }}-$ Verb-Sub ${ }_{\text {dat }} \rightarrow$ Sub $_{\text {nom }}-$ Verb-Sub ${ }_{\text {acc }}$.

V BS se predmetni dajalnik ohranja pri naslednjih glagolih: *modl-i-ti (se) ipf. 'moliti, prositi' (> stcsl. молити (с⿱⿰㇒一十凵) ipf. 'moliti, prositi') (BS i nam ze modliti tomuge vuirchnemo otzu gofzpodi (II 59-61) = i nam sę modliti tomuje vrxńému otcu gospodi 'in nam se je moliti istemu vrhnjemu očetu gospodu'), *sQd-i-ti ipf. 'soditi,

${ }^{27}$ Pomen *`vladati' je najverjetneje nastal iz pomena *‘ukazovati', prvotno gre torej za glagol rekanja. 
presojati' (> stcsl. схаити ipf./pf. 'soditi, presojati') (BS igdafe pride` zodit siuuim i mrtuim (III 56-58) = igdaže prideš sodit živim i mrtvim 'ko boš prišel sodit živim in mrtvim'), *klan-ja-ti se > *klańati sę ipf. 'klanjati se' (> stcsl. кпангати са ipf. 'klanjati se; spoštovati') (BS: clanam ze $i$ modlim ze im (II 36-37) = klańam sę $i$ modlim se jim 'klanjamo se in se jim molimo'), *do-sto-ja-ti ipf. 'spodobiti se, biti prav, biti primerno' (> stcsl. дө-стогати ipf.: дө-стоитъ комоү/чесомоү + Inf. 'spodobi se, prav je, primerno je') (BS imfe ze nam dozftoi od gego zavuekati (II 94-96) = jimže sę nam dostoji od jego zavétati 's čim se nam spodobi od njega ubraniti'). Prvotni pomen ohranja glagol *u-klon-i-ti (se) (> stcsl. oү-кломити ipf. 'odkloniti, odvrniti': оүкпонипъ кси стьsА паша отъ пжти твокго / uklonil jesi stbzę našę otъ poti tvojego (Ps 43, 19) 'Odklonil si naše steze od svoje poti'; оү-кпонити са ipf. 'odkloniti se, odmakniti se') (BS ide necamo ze vcloniti (II 84-85) = ide ně kamo se ukloniti 'ni kam se ukloniti'), ki pa predmeta $\mathrm{v}$ dajalniku nima besedilno aktualiziranega.

\subsection{Glagoli s predložnim sklonom}

V BS se pojavljata dva glagola, ki se vežeta s predložnim sklonom oziroma predmetnim odvisnikom, in sicer *věr-ov-a-ti ipf. 'verovati' (> stcsl. вњровати ipf. 'verovati') (BS tofe uиeruiu u bog uzemogoki (III 4-6) = tože věrujo v bog vsemogoti 'tudi verujem v boga vsemogočega', $i$ vueruiu da mi ie [...] iti fe na on zuet (II 8-9) $=i$ věrujo, da mi je [...] iti že na on svět 'verujem, da mi je iti na oni svet') in *mysl-i-ti ipf. 'misliti' (> stcsl. мыскити ipf. 'misliti; nameravati') (BS da c tomu dini zinzi muzlite (II 83-84) = da k tomu d(2)ni, sinci, myslite 'da na tisti dan, sinki, mislite'). $\mathrm{V}$ obeh primerih gre za glagol umevanja, ki prizadeto izraža s predložnim tožilnikom $\left(* v b(n)_{\text {acc }}\right.$ ) oziroma dajalnikom $\left(* k b(n)_{\text {dat }}\right)$, ki imata preneseni prostorski/krajevni pomen ciljno mesto (direktivni pomen).

\section{Trovezljivi (trivalentni) glagoli}

Trovezljivi (trivalentni) glagoli so dvoprehodni (bitranzitivni) ter imajo osebkov imenovalnik in dva (nepredložna ali predložna) odvisna sklona: $\mathbf{S u b}_{\text {nom }}-\mathbf{V e r b}_{\text {tr }}-\mathbf{S u b}_{\text {cas.obl. }}-$ Sub cas.obl. .

\subsection{Glagoli $z$ imenovanikom, dajalnikom in tožilnikom}

Trovezljivi glagoli z imenovalnikom, dajalnikom in tožilnikom imajo osebkov imenovalnik s pomenom vršilec/vršilnik dejanja, predmetni dajalnik s pomenom prejemnik in predmetni tožilnik s pomenom prizadeto: $\mathbf{S u b}_{\text {nom }}-$ Verb-Sub ${ }_{\text {dat }}-\mathbf{S u b}_{\mathbf{a c c}}$. Glagoli s predmetnim dajalnikom in predmetnim tožilnikom so bili prvotno glagoli dajanja, jemanja, rekanja in učenja. 


\subsubsection{Glagoli dajanja}

Glagoli dajanja v širšem smislu imajo pomene kot *‘dati’, *'darovati’, *‘izročiti’, *'pustiti', *'posoditi', *'plačati, povrniti, nadomestiti', *'žrtvovati', *'nuditi', *'deliti' ( *da-ti pf. 'dati' / *da-ja-ti ipf. 'dajati' in sestavljenke kot *otb-da-ti pf. 'oddati', *po-da-ti pf. 'podati', *pro-da-ti pf. 'prodati', *per-da-ti pf. 'predati', *vb-da-ti pf. 'vročiti', *vbz-da-ti pf. 'vrniti, povrniti'; izpeljanke iz samostalnika *dar-b 'dar, darilo' kot *dar-i-ti ipf. 'darovati', *dar-ov-a-ti ipf. 'darovati'; izpeljanke iz predložnih zvez s samostalnikom *rok-a 'roka' kot *po-roč- $i$ - $t i$ pf. 'izročiti, predati'; *pust-i-ti pf. 'pustiti' / *pust-ja-ti > *puščati ipf. 'puščati' in sestavljenke kot *otb-pust-i-ti pf. 'odpustiti', *o(b)-prost-i-ti pf. 'narediti prosto, pustiti oditi'; *po-sqd-i-ti pf. 'posoditi' / *po-sQd-ja-ti > *po-sQd́ati ipf. 'posojati', *požitzč-i-ti pf. 'posoditi'; *plat-i-ti pf. 'plačati' / *plat-ja-ti > *platati ipf. 'plačati', *želd-ti > *̌̌elsti pf./ipf. 'nadomestiti izgubo, plačati dolg'; *žer-ti/*žbr-ti ipf. 'žrtvovati'; *skyt-a-ti ipf. 'nuditi', *nud-i-ti ipf. 'siliti'; *děl-i-ti ipf. 'deliti’). V slovanskih jezikih glagoli dajanja v večini primerov ohranjajo predmetni dajalnik in predmetni tožilnik.

V BS se pojavljajo naslednji glagoli dajanja: *da-ti pf. 'dati' ( $>$ stcsl. Аати pf. 'dati') (BS dai mi bofe gozpodi tuuoio milozt (III 50-52) = daj mi, bože gospodi, tvoje milost 'daj mi, o bog gospod, svojo milost', ve ze da vmoku za vuiz narod (I 27-28) = uže sę da v moko za vas narod 'že se je dal v trpljenje za ves rod'), *po-rqč-i-ti pf. 'izročiti, predati' (> stcsl. по-ржчити pf. 'zapustiti, zaupati; zaročiti': мьнћ порхчи вогъ соүгоүвь Ааоүидовъ пхть / mьnе̌ porqči bogъ sugubь dauidovъ pQtь 'Meni je zaupal gospod dvojno Davidovo pot') (BS miloztivui bofe tebe poronfo me telo (I 29) = milostivi bože, tebě poročo mě tělo 'o milostljivi bog, tebi izročam svoje telo', tebe bofe miloztivui porufo uza moia zlouuez (III 59-62) = tebě, bože milostivi, poročo vsa moja sloves[a] 'tebi, o bog milostljivi, izročam vse svoje besede'), *za-dё-ti pf. (> stcsl. за-А

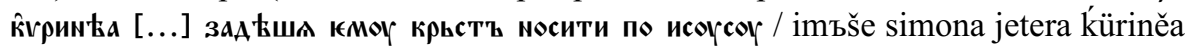
[...] zaděšę jemu krъstъ nositi po isusu 'Potem ko so prijeli nekega Simona iz Cirene, so mu naložili križ nositi za Jezusom') (BS acofe ti mi zadene (I 26) = akože ti mi zadeneš 'kakor mi ti naložiš'). V trpniku se pojavlja glagol *u-gotov-i-ti pf. 'pripraviti' (> stcsl. оү-готовити pf. 'pripraviti') (BS efe v iezt ugotoulieno iz uueka v uuek (I 34-35) = ěze v[i] jest ugotovĺeno iz věka v věk 'kar vam je pripravljeno iz veka v vek', $v$ zezarftuo fuoge efe ieft ugotouleno izvvolenico com bofiem (II 64-6) = v cěsaŕstvo svoje, eže jest ugotovleno [...] izvolenikom božjem 'v cesarstvo svoj, ki je pripravljeno izvoljencem božjim').

\subsubsection{Glagoli jemanja}

Glagoli jemanja v širšem pomenu imajo pomene kot *'jemati', *'krasti, odtujiti' (*ję-ti pf. 'vzeti, zgrabiti, ujeti; začeti' / *jbm-a-ti ipf. 'jemati' in sestavljenke kot

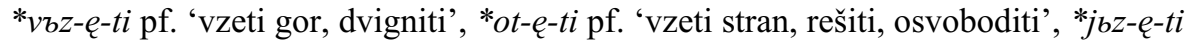
pf. 'vzeti ven'; *krad-ti $>* k r a s t i$ ipf. 'krasti' / *u-krad-ti $>* u$-krasti pf. 'ukrasti'). 
V BS se pojavljata kontinuanta glagolov *vbz-ę-ti in *ot-ę-ti. Glagol *vbz-e-ti pf. 'vzeti gor, dvigniti' / *vъz-ьm-a-ti ipf. 'jemati gor, dvigati' (> stcsl. въз-лти pf. 'vzeti, zgrabiti; prejeti, dobiti', въз-лтти са pf. 'dvigniti se') (BS da bim na zem zuete tacoga grecha pocazen vzel (I 25) = da bim na sem světě takoga grěxa pokazən $v z e ̨ l$ 'da bi na tem svetu takega greha kazen gori vzel') se pojavlja v fraznem glagolu *pokaznb vъzęti 'vzeti gor kazen, biti kaznovan', ${ }^{28}$ ki je nastal, ko je imel glagol *vbzęti še prvotni pomen *'vzeti gor, dvigniti’ (s predmetom v tožilniku s pomenom prizadeto, možen bi bil tudi predmet $\mathrm{v}$ dajalniku s pomenom koristnik, ki pa ni besedilno aktualiziran) in ne drugotnega *'vzeti' (s predmetom v tožilniku s pomenom prizadeto in predmetom v dajalniku s pomenom prejemnik). Glagol *ot-e-ti pf. 'vzeti stran' / *ot-bm-a-ti ipf. 'jemati stran' ( $>$ stcsl. от-лти pf. 'rešiti, osvoboditi, vzeti stran' / от-ьмати ipf. 'jemati stran') (BS da bi ni zlodeiu otel (I 28) = da bi ni zloděju otęl 'da bi nas zlodeju otel', otmi me vzem zlodeiem (I 28-29) = otmi me vsěm zlodějem 'otmi me vsem zlodejem', gemu ze oteti (II 96) = jemu sę otęti 'njemu se oteti') je imel zaradi predpone *ot- s prvotnim ablativnim pomenom najverjetneje prvotno ob sebi tožilnik s pomenom prizadeto in ločilniški rodilnik s pomenom izhodiščno mesto (stcsl. отъими отъ меиє рамъы твою / otъmi otъ mene rany tvoję 'Vzemi stran od mene svoje rane'), v BS pa se pojavlja tožilnik s pomenom prizadeto in dajalnik s pomenom prejemnik. ${ }^{29}$

\subsubsection{Glagoli rekanja}

Glagoli rekanja imajo pomene kot *'reči, govoriti, povedati', *'prerokovati', *'odgovoriti', *'obljubljati, prisegati', *'veleti, ukazati', *'pretiti, groziti', *'rogati se, zasmehovati', *'očitati, sramotiti', *'grajati, karati, zmerjati', *'zahvaliti (se)', *'svetovati', *'tožiti' (*rek-ti > *reti pf. 'reči' / *rěk-a-ti ipf. 'rekati', *govor-i-ti ipf. 'govoriti', *golgol-a-ti ipf. 'govoriti', *vět-i-ti ipf. 'govoriti, pogovarjati se' / *vět-ja-ti $>$ *větati ipf. 'govoriti, pogovarjati se', *po-věd-ě-ti pf. 'povedati', *sb-kaz-a-ti pf. 'razložiti, reči'; *pro-rek-ti > *pro-reti pf. 'prerokovati', *pro-po-věd-ě-ti ipf. 'prerokovati'; glagoli s predpono *ot- s prvotnim ablativnim pomenom kot *otz-vět-i-ti pf. 'odgovoriti' / *otb-vět-ja-ti > *otbvětati ipf. 'odgovorjati'; *ob-vět-i-ti > *obětiti pf. 'obljubiti' / *ob-vět-ja-ti > *obétati ipf. 'obljubljati', *pri-sęg-ti > *pri-sęti pf. 'priseči' / *pri-sez-a-ti ipf. 'prisegati', *klęti sę ipf. 'prisegati', *ob-roč-i-ti pf. 'obljubiti'; *vel-ě-ti ipf. / *po-vel-ě-ti pf. 'veleti, ukazati’; *per-t-i-ti 'pretiti, groziti’; *rog-a-ti se 'rogati se, zasmehovati'; *do-sad-i-ti pf. 'užaliti'; *po-nos-i-ti pf. 'očitati, sramotiti'; *po-ję-ti pf. / *po-jbm-a-ti ipf. 'karati, grajati', *na-da-va-ti ipf. 'zmerjati'; *za-xval-i-ti

${ }^{28}$ Frazni glagoli z glagolom *vbzęti $\mathrm{v}$ stari cerkveni slovanščini so na primer көмьць възати 'vzeti konec, pogubiti se', пачатъкъ възати 'začeti', повђдљ възАти 'zmagati', съмрьть възати 'umreti'.

${ }^{29} \mathrm{~S}$ slabitvijo prostorskega/krajevnega pomena glagolske predpone, ki prvotno določa sklon s prostorskim/krajevnim pomenom, se spremeni tudi glagolska vezava (*ot-ę-ti kogo/ čbto (otz) kogo/česo 'vzeti stran koga/kaj od koga/česa' > *ot-ę-ti kogo/čbto komu/česomu 'vzeti stran koga/kaj komu/čemu'). 
pf. 'zahvaliti', *bolg-o-dar-i-ti ipf. 'zahvaljevati se', *(dęk)-ov-a-ti ipf. 'zahvaljevati se'; *şvět-ov-a-ti ipf. 'svetovati', *(rad)-i-ti ipf. 'svetovati'; *tož-i-ti 'tožiti').

Pri glagolih rekanja v BS tožilnik in dajalnik nista povsod besedilno aktualizirana: “po-věd-a-ti ipf. 'povedati' (> stcsl. по-вłАати ipf. 'povedati') (BS iufe gezim bovvedal (II 88) = jože jesəm povědal 'ki sem jo povedal'), “jbz-po-věd-ě-ti pf. 'izpovedati' (> stcsl. ис-по-выныти pf. 'izpovedati, priznati') (BS tebe izpovuede vueз moi greh (I 2-3) = tebě izpovědě vas moj grěx 'tebi izpovem ves svoj greh', bogu uze mogokeтu izpounede uзe moie greche (III 25-27) = bogu vsemogetému izpovédě vsę moje grěxę 'bogu vsemogočnemu izpovem vse svoje grehe'), *golgol-a-ti ipf. 'besedovati, govoriti' (> stcsl. глаголати ipf. 'govoriti, praviti') (BS glagolite po na3 redka sloveza (I 1) = glagolite po nas rědka slovesa 'govorite za nami maloštevilne besede'), *za-golgol-a-ti se pf. 'odpovedati se' (BS iaz ze zaglagolo zlodeiu (III 1-2) = jaz sę zaglagoĺ zloděju 'jaz se odpovem zlodeju'), *po-čit-ti > *počisti pf. 'našteti' (> stcsl. по-чисти pf. 'spoštovati') (BS im grechi vuafa poftete (II 111-112) = jim grěxi vašę poštěte 'jim grehe svoje naštejte').

\subsubsection{Glagoli učenja}

Glagoli učenja imajo pomene kot *'kazati', *‘učiti (se)', *‘navaditi (se)', *‘znati, vedeti' (*kaz-a-ti ipf. 'kazati' / *po-kaz-a-ti pf. 'pokazati' in sestavljenke kot *na-kaz-a-ti pf. 'poučiti'; *uč-i-ti ipf. 'učiti' / *na-uč- $i$ - $t i$ ipf. 'naučiti', *na-stav-i-ti pf. 'naučiti' / *na-stav-ja-ti > *nastavlati ipf. 'učiti'; *vyk-no-ti ipf. 'navaditi se' / *na-vyk-no-ti pf. 'navaditi se'; *zna-ti ipf. 'znati, vedeti'). V BS se pojavlja glagol *u-kaz-a-ti pf. 'pokazati' (> stcsl. or-казати pf. 'pokazati, predstaviti') (BS ucazal ge imfeze ... (II 94) = ukazal je, jimže ... 'pokazal je, s čim ...') s predmetnim odvisnikom, toda $\mathrm{z}$ besedilno neaktualiziranim dajalnikom.

\subsubsection{Glagoli premikanja}

Glagoli premikanja imajo ob sebi lahko tožilnik in dajalnik, pri čemer je njun pomen odvisen od slovarskega pomena samostalnika v teh sklonih. Če je v dajalniku samostalnik s podspolom živo, ima pomen prejemnik (predmetni dajalnik), če pa samostalnik s podspolom neživo, potem pa pomen ciljno mesto (prislovni dajalnik). V BS se pojavljata oba tipa dajalnika.

Ob glagolu *nes-ti ipf. 'nesti' (> stcsl. мєсти ipf. 'nesti') (BS obeti naffe im nezem (II 38-39) = oběti našę jim nesem 'obete svoje jim nesemo') ima dajalnik jim 'svetnikom' pomen prejemnika, ob glagolu *pri-nes-ti pf. 'prinesti' (> stcsl. при-мести ipf. 'prinesti') (BS ie [...] prinizfe ogni (II 98-100) = je [...] prinesše ogni 'potem ko so jih prinesli k ognju') pa ogni 'k ognju' pomen ciljno mesto (adlativni pomen).

Nekateri glagoli s predpono *pri-s pomenom * 'pridružiti se' (*pri-lěp-i-ti (sę) pf. 'prilepiti (se), pridružiti (se)' / *pri-lěp-ja-ti (se) > *pri-lěplati (se) ipf. 'prilepljati (se), pridruževati (se)', *pri-lož-i-ti pf. 'priložiti, položiti, dati' / *pri-lag-a-ti ipf. 'prilagati', *pri-klad-ti > *pri-klasti pf. / *pri-klad-a-ti ipf. 'posnemati') so prvotno 
ob sebi imeli prislovni mestnik s pomenom mesto (lokativni pomen). V slovanskih jezikih je opazno nadomeščanje mestnika z (nepredložnim ali predložnim) prislovnim dajalnikom s pomenom ciljno mesto (adlativni direktivni pomen): Sub $_{\text {nom }}-{ }_{\text {pri }}-$ Verb-Sub ${ }_{\text {acc }}-$ Sub $_{\text {loc }}>$ Sub $_{\text {nom }}-$ Praef $_{\text {pri }}-$ Verb-Sub ${ }_{\text {acc }}-$ Praep $_{\mathrm{kb}}-$ Sub $_{\text {dat }}$. V BS se pojavlja glagol *pri-bliž-a-ti sę ipf. 'približevati se' (> stcsl. при-влижати са

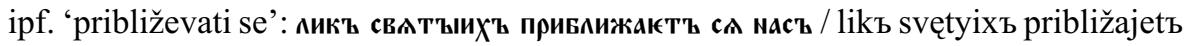
sę nasъ (Evh. 16, 15-16) 'Slavnostni ples in petje svetih se nam približujeta') (BS temi temi ti ze deli bogu briplifaze (II 57-58) = těmi, těmi ti sę děli bogu približašę 's temi, s temi ti so se deli bogu približali'), ki izkazuje novejše stanje z dajalnikom.

\subsection{Glagoli z imenovalnikom, tožilnikom in imenovalnikom}

Nepolnopomenski glagol z oslabljenim slovarskim pomenom, ki so imeli predmetni tožilnik in povedkov imenovalnik, so bili glagoli imenovanja, tj. glagoli s pomenom *'imenovati' v tvornih oziroma *'imenovati se' v povratnih stavkih (*jbmen-ov-a- $t i$ ipf., *na-rek-ti pf. / *na-ric-a-ti ipf., *na-zъv-a-ti pf. / *na-zyv-a-ti ipf.): Sub nom $^{-}$ Verb $_{\text {nominandi }}-$ Sub $_{\text {acc }}-$ Sub $_{\text {nom }} /$ Sub $_{\text {nom }}-$ Verb $_{\text {nominandi }}-\mathbf{S e}_{\text {acc }}-$ Sub $_{\text {nom }}$. V BS se pojavlja glagol *na-rek-ti > *na-reti pf. 'imenovati' (> stcsl. ма-решти pf. ти съмове вожии марекхтъ с⿱ / ti synove božii narekǫtъ sę 'Ti se božji sinovi imenujejo') (BS zinouue bofi narefem ze (II 16-17) = sinove božji narečem sę 'sinovi božji imenujemo se').

\subsection{Glagoli $\mathrm{z}$ imenovalnikom, tožilnikom in rodilnikom oziroma orodnikom}

Glagoli s predmetnim tožilnikom in predmetnim rodilnikom ali orodnikom so glagoli polnjenja s predpono *na- in s pomeni kot*'napolniti', *'naliti', *'naložiti', *'nahraniti, nasititi, napojiti' (*na-pbln-i-ti pf. 'napolniti'; *na-li-ti pf. 'naliti', *na-syp-a-ti 'naliti', *na-moč-i-ti pf. 'namočiti'; *na-lož-i-ti pf. 'naložiti', *na-stbl-a-ti pf. 'nastlati'; *na-tru-ti pf. 'nahraniti', *na-syt-i-ti pf. 'nasititi', *na-poj-i-ti pf. 'napojiti', *na-sold-i-ti se pf. 'okusiti, potešiti se, užiti'): ${ }^{30}$ Sub $_{\text {nom }}{ }^{-}$ Verb plendi $_{\text {Subc }}-$ Sub $_{\text {gen }} /$ Sub $_{\text {instr }}$.

V BS pri dveh izpričanih glagolih polnjenja predmetni rodilnik oziroma orodnik besedilno ni aktualiziran: *na-tru-ti pf. 'nahraniti, nakrmiti' (> stcsl. ма-трогти pf. 'nahraniti, nakrmiti': матровеши мъ Хићва сльзьма / natroveši ny xlěba slbzьna (Ps $80(79), 6)$ 'Nasitil nas boš s solznim kruhom') (BS lafna natrovuechu (II 44-45) = lačna natrověxg 'lačnega so nahranili'), *na-poj-i-ti pf. 'napojiti' (> stcsl. ма-поити pf. 'napojiti, dati piti': мапоиша ма оцьта / napoišę mę ocьta (Ps. 69 (68), 22) 'Napojili so me s kisom’) (BS Jegna naboiachu (II 45-46) = žejna napojaxQ ‘žejnega so napojili').

${ }^{30}$ Miklosich 1883: 505-507; Vondrák 1928: 243. 


\subsection{Glagoli z imenovalnikom, tožilnikom in ločilniškim rodilnikom}

To so prehodni glagoli najpogosteje s predponami *ot(b)- 'od-', *u- 'stran', *jbz-/*vy'iz-', *sz- 'z-/s-' s prvotnim ablativnim pomenom *'iti od' z osebkovim imenovalnikom s pomenom vršilec/vršilnik dejanja, predmetnim tožilnikom s pomenom prizadeto in prislovnim ločilniškim rodilnikom s pomenom izhodiščno mesto (ablativni pomen). Prvotno je bil ločilniški rodilnik najverjetneje brez predloga, drugotno pa je bil njegov ablativni pomen pomensko natančneje določen s predlogi, in sicer ablativno (*ot(b) 'od, stran, proč'), elativno ( $*_{j b z}$ 'od notri'), sublativno ( ${ }_{s b}$ 'od zgoraj'): Sub ${ }_{\text {nom }}$-Verb-

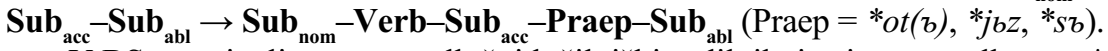

V BS se pojavlja samo predložni ločilniški rodilnik, in sicer s predlogom *ot(b), z glagolom v tvorniku ali trpniku. V tvorniku se pojavljata glagola *jbz-bav-i-ti pf. 'odrešiti' (> stcsl. из-ваиити pf. 'rešiti, oteti, osvoboditi') (BS grefnike ifbauuiti ot zlodeine oblazti (III 69-71) = grěšnike izbaviti ot zlodějnę oblasti 'grešnike rešiti od zlodejeve oblasti') in *u-xorn-i-ti pf. 'obvarovati, obraniti' (stcsl. Хранити ipf. 'ščititi, varovati, braniti, ohranjevati') (BS uchrani me ot uzega zla (III 72-73) = uxrani me ot vsega zla 'obvaruj me od vsega zla'), v trpniku pa glagola *jbz/vy-gъn-a-ti pf. 'izgnati' (> stcsl. из-гъмати/въ-гъмати pf. 'izgnati': изг'ъма са сана / izgъna sę sana 'Izgnal se je od položaja') (BS zavuiztiu bui nepriiazninu uvignan od fzlauui bofige (II 8-10) = zavistjo by Neprijaznino vignan ot slavy božję 'z zavistjo je bil Neprijaznega izgnan od slave božje') in *za-vět-ja-ti > *zavětati pf. 'odreči' (> stcsl. за-вŁштати pf. 'obljubiti; zavrniti') (BS imfe ze nam dozftoi od gego zavuekati (II 94-96) = jimže sę nam dostoji od jego zavétati 's čim se nam spodobi od njega ubraniti'). Ločilniški rodilnik ni besedilno aktualiziran pri glagolu *sb-pas-ti pf. 'rešiti' ( $>$ stcsl. съ-пасти pf. 'rešiti, obvarovati, zaščititi') (BS zpazi me v uzem blafe (III 73) = spasi mę v vsem blazě 'reši me v vsem dobrem').

\section{Literatura}

AGSČ: Akademická gramatika spisovné češtiny. Ur. František Štícha. Praha: Academia, 2013.

Babič, Vanda. 2003. Učbenik stare cerkvene slovanščine. Ljubljana: Filozofska fakulteta Univerze v Ljubljani: Oddelek za slavistiko, Oddelek za slovenistiko.

Bajec, Anton, Kolarič, Rudolf, Rupel, Mirko. 1956. Slovenska slovnica. Ljubljana: Državna založba Slovenije

Bezlaj, France. 1976, 1982, 1995, 2005, 2007. Etimološki slovar slovenskega jezika I-V. Ljubljana: Slovenska akademija znanosti in umetnosti, Inštitut za slovenski jezik ZRC SAZU.

Brižinski spomeniki / Monumenta Frisigensia: Znanstvenokritična izdaja, ${ }^{3} 2004$ ('1992, $\left.{ }^{2} 1993\right)$. Ljubljana: Slovenska akademija znanosti in umetnosti.

Dardano, Maurizio, Trifone, Pietro. 1995. Grammatica italiana con nozioni di linguistica. Bologna: Zanichelli.

Delbrück, Berthold. 1893. Grundriss der vergleichenden Grammatik der indogermanischen Sprachen, III/1. Vergleichende Syntax der indogermanischen Sprachen. Strassburg: Karl J. Trübner. 
Dular, Janez. 1983/1984. Združena vezava v desni vezljivosti slovenskega glagola. Jezik in slovstvo 29/8: 289-293.

Eisenberg, Peter, et al. 1998. Die Grammatik. Mannheim, Leipzig, Wien, Zürich: DUDEN.

Fillmore, Charles J. 1968. The case for case. Universals in Linguistic Theory. Ur. E. Bach, R. Harms. New York, Holt, Rinehart, Winston. 1-88.

Граматика на старобългарския език: Фонетика, морфология, синтаксис, 1993. Главен редактор Иван Дуриданов. София: Българска академия на науките

Golden, Marija. 2000. Teorija opisnega jezikoslovja: 1. Skladnja. Ljubljana: Filozofska fakulteta Univerze v Ljubljani, Oddelek za primerjalno in splošno jezikoslovje.

Grošelj, Robert. 2011. Vezava glagolov umevanja v slovanskih jezikih. Ljubljana: Znanstvena založba Filozofske fakultete Univerze v Ljubljani.

Hock, Hans Henrich. ${ }^{2} 1991$ (1986). Principles of Historical Linguistics. Berlin, New York: Mouton de Gruyter.

Jakobson, Roman. 1936. Beitrag zur allgemeinen Kasuslehre: Gesamtbedeutungen der russischen Kasus. Travaux du Cercle Linguistique de Prague 7. Prague. 240-288.

Križaj-Ortar, Martina. 1982. Glagolska vezljivost. Slavistična revija 30/2: 189-213.

Križaj-Ortar, Martina. 1989. Vezljivost: iz pomena v izraz. 26. seminar slovenskega jezika, literature in kulture. Ur. Tone Pretnar. Ljubljana: Filozofska fakulteta Univerze v Ljubljani, Oddelek za slovanske jezike in književnosti. 123-140.

Kunst Gnamuš, Olga. 1981. Pomenska sestava povedi. Ljubljana: Pedagoški inštitut pri Univerzi Edvarda Kardelja v Ljubljani.

Marvin, Tatjana. 2012. A Note on Applicatives. Syntax and Semantics 38: The End of Argument Structure? Uredila M. C. Cuervo and Y. Roberge. Bingley, UK: Emerald.

MČ 3: Mluvnice češtiny 3: Skladba. Praha: Academia, 1987.

Meškank, Timo. 2009. Aussagenstruktur im Sorbischen: Untersuchungen zur Syntax und Satzsemantik I-II. Hamburg: Verlg Dr. Kovač.

Meier - Brügger, Mihael. ${ }^{3} 2010$ (12001). Indogermanische Sprachwissenschaft. Berlin, New York: Walter de Gruyter.

Miklosich, Franz. 1862-1865. Lexicon Palaeoslovenisco-Graeco-Latinum. Wien: Verlagbuchhandlung Wilhelm Braumüller.

Miklosich, Franz. 1883. Vergleichende Grammatik der slavischen Sprachen: IV. Syntax. Wien.

Orešnik, Janez. 1992. Udeleženske vloge v slovenščini. Ljubljana: Slovenska akademija znanosti in umetnosti.

Pavlović, Slobodan. 2011. Prostor i prostorne metafore u padežnom sistemu Brižinskih spomenika. Slavistična revija 59/2. 179-194.

Pogorelec, Breda. 1981/1982. Povzetek slovenske skladnje: Tipi prostega stavka. Ljubljana: tipkopis, 27 strani.

Rix, Helmut. 1977. Das keltische Verbalsystem auf dem Hintergrund des indo-iranisch-griechischen Rekonstruktionsmodells. Keltisch und Indogermanisch. Kolloquium der Indogermanischen Gesellschaft, Bonn, 1976. Bonn. 123-158.

Smolej, Mojca. 2011. Skladnja slovenskega knjižnega jezika: Izbrana poglavja z vajami. Knjižna zbirka Scripta. Ljubljana: Študentska založba.

Snoj, Marko. ${ }^{2} 2003$ (11997). Slovenski etimološki slovar. Ljubljana: Modrijan.

Старославянский словарь (по рукописям X-XI веков), ${ }^{2} 1999$ ('1994). Москва: Издательство «Русский язык».

Šekli, Matej. 2011. Besedotvorni pomeni nesestavljenih izpeljanih glagolov v (pra)slovanščini. Globinska moč besede: Red. prof. dr. Martini Orožen ob 80-letnici. Zbirka Zora 80. Uredil Marko Jesenšek. Bielsko-Biała, Budapest, Kansas, Maribor, Praha. 32-45. 
Šekli, Matej. 2012. Praslovanski besedotvorni vzorci izpeljave drugotnih nedovršnih glagolov. Jezikoslovni zapiski 18/1: 7-26.

Šekli, Matej. 2013. K Miklošičevi primerjalni skladnji sklonov slovanskih jezikov. Družbena funkcijskost jezika: vidiki, merila, opredelitve. Obdobja 32. Uredila Andreja Žele. Ljubljana: Znanstvena založba Filozofske fakultete. 427-433.

Toporišič, Jože. 1982. Nova slovenska skladnja. Maribor: Obzorja.

Toporišič, Jože. ${ }^{4} 2000$ (1976). Slovenska slovnica. Maribor: Obzorja.

Večerka, Radoslav. 2006. Staroslověnština v kontextu slovanských jazyků. Olomouc, Praha: Univerzita Palackého v Olomouci, Nakladatelství Euroslavica.

Vondrák, Wenzel. ${ }^{2} 1928$ (1908). Vergleichende Slavische Grammatik II: Formenlehre und Syntax. Göttingen: Vandenhoeck \& Ruprecht.

Žele, Andreja. 2000. Vezljivostna teorija v slovenskem jezikoslovju. Slovenski jezik / Slovene Linguistic Studies 3. 68-90.

Žele, Andreja. 2001. Vezljivost v slovenskem jeziku. Ljubljana: Inštitutut za slovenski jezik Frana Ramovša ZRC SAZU.

Žele, Andreja. 2003. Glagolska vezljivost iz teorije v slovar. Ljubljana: Inštitutut za slovenski jezik Frana Ramovša ZRC SAZU.

Žele, Andreja. 2008. Vezljivostni slovar slovenskih glagolov. Ljubljana, 2008: Inštitutut za slovenski jezik Frana Ramovša ZRC SAZU.

Žele, Andreja. 2011. Vezljivostni slovar slovenskih glagolov: Skrajšana knjižna izdaja. Ljubljana: Inštitutut za slovenski jezik Frana Ramovša ZRC SAZU.

Prispelo maja 2015, sprejeto junija 2015

Received May 2015, accepted June 2015

\section{Glagolska vezljivost v jeziku Brižinskih spomenikov}

Primerjava glagolske vezljivosti (verbalne valence) glagolov, ki se pojavljajo v jeziku Brižinskih spomenikov (10. stoletje), s stanjem v stari cerkveni slovanščini ( 9 . stoletje) in rekonstruiranim praslovanskim stanjem pokaže, da je na časovni osi praslovanščina - slovenščina 10. stoletja prišlo do naslednjih inovacij v glagolski vezavi (verbalni rekciji): a) predmetni rodilniški rodilnik je bil zamenjan s predmetnim tožilnikom ( $\mathrm{Sub}_{\text {nom }}-$ Verb-Sub ${ }_{\text {gen }} \rightarrow \mathrm{Sub}_{\text {nom }}-$ Verb-Sub ${ }_{\text {acc }}$ ) pri glagolih *jbméti 'imeti', *prijęti 'prijeti', *uslišati 'zaslišati', *vъznenaviděti 'zasovražiti', *vъzlubiti 'vzljubiti'; b) predmetni brezpredložni ločilnik ob glagolih nepremikanja se je zamenjal s predmetnim brezpredložnim tožilnikom $\left(\mathrm{Sub}_{\text {nom }}-\mathrm{Verb}_{\text {-movendi }}-\mathrm{Sub}_{\mathrm{abl}} \rightarrow \mathrm{Sub}_{\text {nom }}-\mathrm{Verb}_{\text {-movendi }}\right.$ $-\mathrm{Sub}_{\text {acc }}$ ) pri glagolu *poščęděti 'obvarovati, prihraniti, prizanesti'; c) prislovni brezpredložni ločilnik večinoma ob glagolih premikanja se je zamenjal s predložnim prislovnim ločilnikom $\left(\mathrm{Sub}_{\text {nom }}-\mathrm{Verb}_{+ \text {movendi }}\left(-\mathrm{Sub}_{\mathrm{acc}}\right)-\mathrm{Sub}_{\mathrm{abl}} \rightarrow \mathrm{Sub}_{\text {nom }}-\mathrm{Verb}_{+ \text {movendi }}\right.$ $\left(-\mathrm{Sub}_{\mathrm{acc}}\right)-$ Praep-Sub $\left.{ }_{\mathrm{abl}}\right)$ pri glagolih *jbzbaviti 'odrešiti', *uxorniti 'obvarovati, 
obraniti', *vygъnati 'izgnati', *zavětati sę 'odreči se'; č) pri glagolih s predpono *pri-s pomenom *'pridružiti se' se je prislovni mestnik zamenjal z (nepredložnim ali predložnim) prislovnim dajalnikom $\left(\mathrm{Sub}_{\text {nom }}-\mathrm{Praef}_{\text {pri }}-\mathrm{Verb}-\mathrm{Sub} \mathrm{acc}_{-\mathrm{Sub}} \rightarrow \mathrm{Sub}_{\text {nom }}-\right.$ Praef $_{\text {pri }}-$ Verb-Sub ${ }_{\text {acc }}-$ Praep $_{\mathrm{kb}}-S_{\text {dat }}$ ) pri glagolu *približati se 'približati se'.

\section{Verb valency in the Freising Monuments}

On the basis of comparison of verb valency in 10th century Slovene as attested in the Freising Monuments with the system observable in Old Church Slavonic (9th c. AD) and that which can be securely reconstructed for the Proto-Slavic stage, it is possible to identify the following trends of progressive change in verb government: a) verbs such as *jbměti 'to have', *prijęti 'to grab', *uslišati 'to hear', *vbznenavidéti 'to hate', *vzzlubiti 'to love' originally governing an objective genitive tend to assign the accusative to the direct object ( $\mathrm{Sub}_{\text {nom }}-$ Verb-Sub $\left.\mathrm{gen}_{\rightarrow} \rightarrow \mathrm{Sub}_{\text {nom }}-\mathrm{Verb}-\mathrm{Sub}_{\mathrm{acc}}\right)$; b) with *poščęéti 'to protect, shelter' the direct object in the non-prepositional ablative with non-motion verbs was displaced by the direct object in the non-prepositional accusative $\left(\mathrm{Sub}_{\text {nom }}-\mathrm{Verb}_{\text {-movendi }}-\mathrm{Sub}_{\mathrm{abl}} \rightarrow \mathrm{Sub}_{\text {nom }}-\mathrm{Verb}_{\text {-movendi }}-\mathrm{Sub}_{\mathrm{acc}}\right)$; c) with $*_{j b z b a v i t i}$ 'to save', *uxorniti 'to shalter', *vygznati 'to expel', *zavétati sę 'to renounce' the prepositional ablative (mostly associated with motion verbs) displaced the older nonprepositional ablative case of the governed adjunct $\left(\mathrm{Sub}_{\text {nom }}-\mathrm{Verb}_{+ \text {movendi }}\left(-\mathrm{Sub}_{\mathrm{acc}}\right)-\mathrm{Sub}_{\mathrm{abl}}\right.$ $\rightarrow \mathrm{Sub}_{\text {nom }}-\mathrm{Verb}_{+ \text {movendi }}\left(-\mathrm{Sub}_{\mathrm{acc}}\right)-$ Praep-Sub $\left.\left.{ }_{\mathrm{abl}}\right) ; \mathrm{d}\right)$ prefixed verbs involving *pri- with the associative function * 'to join', e.g., *približati se 'to approach, come near' originally governing a (non-)prepositional locative assign the dative case to the adjunct $\left(\mathrm{Sub}_{\text {nom }}-\right.$ Praef $_{\text {pri }}-$ Verb-Sub ${ }_{\text {acc }}-\mathrm{Sub}_{\mathrm{loc}} \rightarrow \mathrm{Sub}_{\text {nom }}-$ Praef $\left._{\text {pri }}-\mathrm{Verb}_{-} \mathrm{Sub}_{\mathrm{acc}}-\mathrm{Praep}_{\mathrm{kb}}-\mathrm{Sub}_{\mathrm{dat}}\right)$. 